\title{
Sistema Híbrido: Raciocínio Baseado em Casos e Redes Neurais ${ }^{1}$
}

\author{
Claudia Regina Milaré
}

\begin{abstract}
Orientação:
Prof. Dr. André Carlos Ponce de Leon Ferreira de Carvalho
\end{abstract}

Dissertação apresentada ao Instituto de Ciências Matemáticas de São Carlos, Universidade de São Paulo, como parte dos requisitos para obtençáa do Título de Mestre junto à Área de Ciências de Computação e Matemática Computacional.

USP - São Carlos

Agosto de 1997.

\footnotetext{
${ }^{1}$ Trabalho realizado com auxílio do $\mathrm{CNPq}$.
} 
A meus pais, Idio e Armelinda, pelo amor, dedicação e incentivo. 


\section{Agradecimentos}

Ao meu orientador, professor André, pela competente supervisão, pela amizade e paciência, e principalmente, por sempre compreender minhas limitações;

À professora Carolina, pelas sugestões, pelo apoio e pela atenção com que me dedicou nestes anos;

À professora Solange, pela amizade e incentivo em todos os momentos;

Ao Werner e à Flávia, que me auxiliaram neste trabalho;

Aos meus amigos Andréia, Gustavo, Jaqueline e aos amigos da República dos Margaridas;

Aos funcionários do Instituto de Ciências Matemáticas de São Carlos;

Aos meus irmãos Márcia e Idinho; ao Osvaldo, Graziela e Elisa; à toda minha família e ao Fernando, que sempre me incentivaram e torceram por mim;

Ao CNPq pelo apoio financeiro;

Àqueles que de um modo ou de outro contribuíram para a realização deste trabalho;

À Deus, que sempre está ao meu lado. 


\section{Resumo}

Os processos de recuperação e aprendizado de casos, que exercem um papel fundamental, em sistemas de Raciocínio Baseado em Casos, não são fáceis de serem desenvolvidos. Estes dois processos são bastante dependentes. Os casos devem ser recuperados rapidamente da memória para o sistema de Raciocínio Baseado em Casos ser eficiente. Isto implica em estruturas mais elaboradas para armazenálos, organizá-los e recuperá-los. Quando um conhecimento novo é incorporado ao sistema (aprendizado), a reorganização dos casos na memória torna-se muito complexa devido justamente à estas estruturas.

O principal objetivo deste trabalho é a integração de Raciocínio Baseado em Casos e Redes Neurais. Neste trabalho, uma Rede Neural, modelo ART1, é utilizada para auxiliar na recuperação e aprendizado de casos em um sistema de Raciocínio Baseado em Casos. 


\begin{abstract}
The retrieval and learning phases, which plays a fundamental role in a Case Based Reasoning system, usually are not easy to design. These processes strongly depend on each other. For a Case Based Reasoning system to be considered efficient, suitable cases must be fastly retrieved. For such, complex structures have been used. However, these structures makes harder the learning of new cases.

This work proposes a Case Based Reasoning system which uses Neural Networks to retrieve stored cases and learn new cases. The network used, ART1, supports incremental learning and groups cases in clusters by extracting features from the cases, which can later be used to retrieve cases.
\end{abstract}




\section{Sumário}

1 Introdução 1

1.1 Motivação e Relevância . . . . . . . . . . . . . . . . . 1

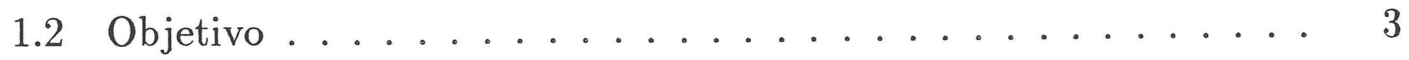

1.3 Organização do Trabalho . . . . . . . . . . . . . 3

2 Redes Neurais 5

2.1 Introdução ......................... 5

2.2 Histórico .......................... 6

2.3 Características de Redes Neurais . . . . . . . . . 8

2.3.1 Unidades de Processamento . . . . . . . . . . 8

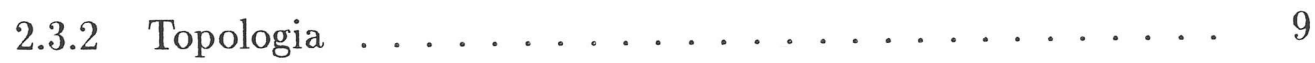

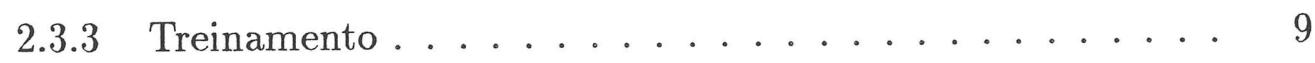

2.4 Principais Modelos ... . . . . . . . . . . . 10

2.4 .1 Perceptron.......................... 10

2.4 .2 Adaline ........................... 11

2.4.3 Perceptron Multi-Camadas .............. 11

2.4.4 Rede de Hopfield ... . . . . . . . . . . 13

2.4.5 Rede Auto-Organizável de Kohonen . . . . . . . . . 14 
2.4 .6 Rede ART ...................... 14

2.5 Conclusão . . . . . . . . . . . . . . . . . . 15

3 O Modelo ART $\quad 16$

3.1 Introdução . . . . . . . . . . . . . . . 16

3.2 Características Gerais de ART . . . . . . . . . . 17

3.2.1 Arquitetura Básica de ART ............ 17

3.2.2 Treinamento................... 19

3.3 Aprendizado em ART1 . . . . . . . . . . . . 20

3.3 .1 Inicialização . . . . . . . . . . . . . . . 20

3.3.2 Reconhecimento................. 20

3.3.3 Comparação . . . . . . . . . . . . . . 21

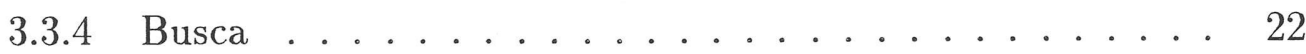

3.4 Exemplo .......................... 22

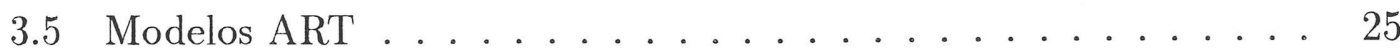

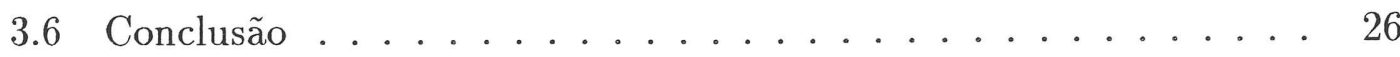

4 Raciocínio Baseado em Casos: uma Visão Geral 28

4.1 Introdução . . . . . . . . . . . . . . . . . 28

4.2 Origens e História de RBC . . . . . . . . . . . . . 30

4.3 Como Funciona um Sistema de RBC . . . . . . . . . . 31

4.3.1 Representação de Casos ... . . . . . . . . . 31

4.3 .2 Indexação de Casos . . . . . . . . . . . . . 33

4.3.3 Armazenamento e Recuperação de Casos . . . . . . . . . 34

4.3.4 Adaptação de Casos . . . . . . . . . . . 35 
4.3.5 Avaliação e Reparo de Casos . . . . . . . . . . . 35

4.4 Estilos de Raciocínio Baseado em Casos . . . . . . . . . 36

4.5 Raciocínio Baseado em Casos e Redes Neurais . . . . . . . . . 37

4.5.1 Combinações Prévias . . . . . . . . . . . . 37

4.6 Conclusão . . . . . . . . . . . . . . . . . . . . 39

5 Recuperar e Aprender Casos $\quad \mathbf{4 0}$

5.1 Introdução . . . . . . . . . . . . . . . . . . 40

5.2 Algoritmos de Recuperação . . . . . . . . . . . . . . . . 41

5.2.1 Memória Plana - Busca Serial/Busca Paralela . . . . . . 42

5.2.2 Rede de Características Compartilhadas - Busca em Largura 44

5.2.3 Redes de Discriminação por Prioridade - Busca em Profundidade .................... 4. 46

5.2.4 Redes de Discriminação Redundante - Busca em Largura . 47

5.2.5 Memória Hierárquica - Busca Paralela . . . . . . . . . 49

5.3 Conclusão . . . . . . . . . . . . . . . . . . . . 49

6 Um Sistema Híbrido de RBC para o Domínio da Culinária 51

6.1 Introdução . . . . . . . . . . . . . . . . 51

6.2 Domínio . . . . . . . . . . . . . . . . 52

6.3 Arquitetura do Protótipo . . . . . . . . . . 54

6.4 Experimento......................... 57

6.5 Avaliando o Modelo Proposto ............... 61

6.5.1 K-Nearest Neighbor ..................... 61

6.6 Conclusão . . . . . . . . . . . . . . . . . . . 63 
7.1 Sobre o Trabalho ................... 64

7.2 Limitações do Modelo . . . . . . . . . . . . . . . 66

7.3 Contribuições . . . . . . . . . . . . . . . . 67

7.4 Trabalhos Futuros . . . . . . . . . . . . . 67 


\section{Lista de Figuras}

2.1 Unidade de processamento proposta por McCulloch e Pitts. . . . 8

2.2 Exemplo da função lógica OR (adaptado de [Beale 90]) . . . . . 10

2.3 Exemplo da função lógica XOR (adaptado de [Beale 90]). . . . . . 11

2.4 Perceptron Multi-Camadas. . . . . . . . . . . . . 12

2.5 Resolução da Função XOR (adaptado de [Beale 90]). . . . . . . . 13

2.6 Rede de Hopfield. . . . . . . . . . . . . . . . . 13

2.7 Rede de Kohonen. . . . . . . . . . . . . . . . . 14

3.1 Arquitetura básica de ART. ................. 18

3.2 Os pesos na arquitetura de ART. .............. 19

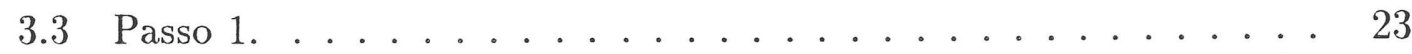

3.4 Passo 2. . . . . . . . . . . . . . . . . . . . 24

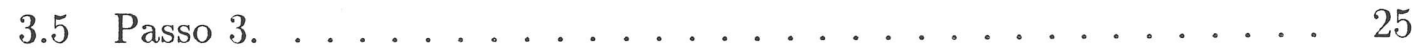

4.1 Idéia básica para resolver problemas. . . . . . . . . . . 29

4.2 Ciclo de um sistema de RBC (adaptado de [Aamodt 94]). . . . . 32

5.1 Casos sequencialmente organizados. . . . . . . . . . 43

5.2 Cada caso é designado à um processador. . . . . . . . . . . 44

5.3 Rede de características compartilhadas (adaptada de [Kolodner 93]). 45 
5.4 Rede de discriminação por prioridade (adaptada de [Kolodner 93]). 47

5.5 Redes de discriminação redundante. . . . . . . . . . . . . 48

5.6 Casos são organizados em hierarquias. . . . . . . . . . . 50

6.1 Arquitetura geral do protótipo de um sistema de RBC. . . . . . . 54

6.2 Estrutura de armazenamento dos casos. . . . . . . . . . 58

6.3 Padrão com 5 posições. . . . . . . . . . . . . . . . . . . 59

6.4 Padrão duplicado. . . . . . . . . . . . . . . . . 60 


\section{Lista de Tabelas}

3.1 Resultado da primeira aplicação da regra $2 / 3 . \ldots . . . . . .23$

3.2 Resultado da segunda aplicação da regra $2 / 3$. . . . . . . . . 24

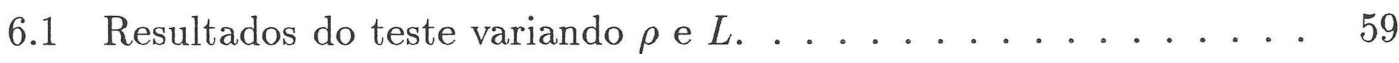

6.2 Resultados do teste variando $\rho$ e $L$. . . . . . . . . . . . 60

6.3 Variando $K$ no algoritmo $K$-Nearest Neighbor. . . . . . . . . 62

6.4 Resultados obtidos a partir do conjunto de treinamento. . . . . 62

6.5 Resultados obtidos a partir do conjunto de teste. . . . . . . . 63 


\section{Capítulo 1}

\section{Introdução}

\subsection{Motivação e Relevância}

Atualmente, há um grande interesse dos pesquisadores em combinar mais de um paradigma para solucionar problemas. Sistemas com esta característica são denominados Sistemas Híbridos [Goonatilake 95]. O que se espera ao integrar várias técnicas é obter um resultado mais eficiente na resolução de problemas, combinando o que cada técnica envolvida tem de mais eficiente. Este trabalho objetiva justamente isto, combinar processamento neural e simbólico, Redes Neurais (RN) e Raciocínio Baseado em Casos (RBC).

RBC é um paradigma de Inteligência Artificial que resolve problemas por analogia. Basicamente, RBC utiliza experiências prévias (casos) para solucionar problemas correntes [Aamodt 94]. Mais do que isto, RBC significa adaptar soluções antigas para atender novas necessidades, utilizar casos passados para explicar novas situações, utilizar experiências prévias para criticar novas soluções, ou raciocinar a partir de precedentes para interpretar uma situação semelhante [Kolodner 93]. Diferente dos Sistemas Especialistas, a experiência anterior é mais importante que o conhecimento geral do problema, isto é, este método entende e resolve novos problemas utilizando conhecimento ou experiência anterior através de um processo de analogia. Por isto, Raciocínio Baseado em Casos é também conhecido como resolução por lembrança.

A construção de um sistema de RBC envolve vários problemas. Os casos prévios que irão compôr a Base de Casos do sistema devem ser representados e armazenados em uma estrutura que possibilite sua posterior recuperação. Geralmente, um sistema de RBC deve ter mecanismos para: representação de casos, indexação de 
casos, recuperação de casos, reuso de casos, revisão/reparo de casos e armazenamento de casos (aprendizado). Quando um problema é apresentado a um sistema de RBC, este deve buscar em sua Base de Casos um caso prévio que seja idêntico ou semelhante ao problema apresentado na entrada do sistema. Em seguida, o sistema pode reusar a solução do caso recuperado para atender às necessidades do novo caso. A solução adaptada será testada e poderá ou não ser incorporada ao sistema.

Devido à sua simplicidade, um número crescente de pesquisadores estão utilizando RBC para o projeto de sistemas inteligentes [Kolodner 93, Aamodt 94]. A idéia básica é que a solução de problemas utilizando casos passados relevantes é uma abordagem muito natural para seres humanos. Este é o processo normalmente utilizado por especialistas para resolver um novo problema de uma maneira rápida e segura. Assim, o poder deste paradigma vem de sua habilidade em recuperar casos relevantes da memória de forma rápida e precisa. Este trabalho focaliza a recuperação e o aprendizado de casos de um sistema de Raciocínio Baseado em Casos auxiliado por uma Rede Neural.

Redes Neurais Artificiais, ou simplesmente Redes Neurais, são sistemas paralelos distribuídos, compostos por unidades de processamento simples (neurônios). Estas unidades computam certas funções matemáticas e estão dispostas em uma ou mais camadas, interligadas por um grande número de conexões. Geralmente, estas conexões estão associadas a pesos, os quais armazenam o conhecimento representado no modelo, e servem para ponderar a entrada recebida por cada neurônio da rede. Em Redes Neurais, o procedimento usual na solução de problemas passa inicialmente por uma fase de aprendizagem, no qual conjuntos de exemplos representativos das classes de padrões são apresentados à rede, que extrai automaticamente, através de um algoritmo de aprendizagem ou treinamento, as características necessárias para representar implicitamente os padrões. Estas características são utilizadas posteriomente pela rede, durante a sua fase de uso, para classificar outros padrões em função de seu grau de similaridade com as representações armazenadas na rede. Dentre as principais características de Redes Neurais pode-se citar:

- Aquisição direta de conhecimento sobre um determinado domínio, através de um processo de treinamento.

- Capacidade de aprendizado.

- Rapidez com que o conhecimento que a rede representa pode ser acessado e utilizado. 
- Capacidade de generalização, ou seja, produzir respostas para padrões de entrada que são similares, mas não idênticos, aos padrões apresentados à rede durante o treinamento.

- Forma compacta (completamente numérica) em que o conhecimento adquirido é armazenado em uma Rede Neural.

Raciocínio Baseado em Casos e Redes Neurais têm sido combinados em pesquisas recentes [Krovvidy 93, Malek 95, Reategui 94, Reategui 95]. Nestas combinações, Redes Neurais são utilizadas principalmente nos processos de recuperação de casos em um sistema de Raciocínio Baseado em Casos.

\subsection{Objetivo}

O objetivo principal deste trabalho é a integração dos paradigmas conexionista utilizando Redes Neurais e simbólico utilizando Raciocínio Baseado em Casos. Em sistemas de Raciocínio Baseado em Casos quanto mais eficiente é a recuperação de casos da memória, melhor o desempenho do sistema. Geralmente, a organização destes casos na memória torna-se muito complexa devido às estruturas necessárias para indexá-los e armazená-los para posteriormente recuperá-los eficientemente. Outra dificuldade no desenvolvimento de sistemas de Raciocínio Baseado em Casos é o aprendizado, já que para um novo caso ser incorporado ao sistema, deve-se reorganizar os casos da memória.

A proposta deste trabalho é integrar Raciocínio Baseado em Casos e Redes Neurais aplicado ao domínio culinário, procurando tornar o processo de recuperação dos casos da memória mais eficiente e ao mesmo tempo surportar um contínuo processo de aprendizado de novos casos. Para isto, uma Rede Neural do tipo ART1 é utilizada para auxiliar os processos de recuperação e aprendizado em um protótipo de um sistema de Raciocínio Baseado em Casos.

\subsection{Organização do Trabalho}

Este trabalho está organizado em sete capítulos. Este capítulo descreve brevemente os paradigmas investigados neste trabalho, bem como o objetivo pretendido e a abordagem prosposta. 
No capítulo seguinte, Capítulo 2, é apresentada uma descrição suscinta de Redes Neurais. Como será visto, esta tecnologia é cada vez mais utilizada em aplicações as quais envolvem as mais diversas áreas.

O Capítulo 3 descreve um modelo particular de Redes Neurais, o modelo ART. A rede ART possui uma característica muito interessante a este trabalho, aprendizado incremental.

No Capítulo 4, a abordagem simbólica utilizada, Raciocínio Baseado em Casos, é descrita. Neste capítulo são também apresentados alguns trabalhos envolvendo a integração de Raciocínio Baseado em Casos e Redes Neurais.

O Capítulo 5 refere-se à relação existente entre a organização de casos na memória, os algoritmos de recuperação destes casos e o processo de aprendizado. Algumas estratégias organizacionais dos casos na memória e os algoritmos de recuperação correspondentes à cada organização são descritos.

O Capítulo 6 descreve o protótipo implementado. São apresentados alguns trabalhos prévios que utilizaram o domínio culinário, bem como os testes realizados e seus resultados.

Finalmente, o Capítulo 7 diz respeito às conclusões sobre o trabalho de um modo geral e suas limitações. São sugeridos também trabalhos futuros que poderão ser desenvolvidos posteriormente envolvendo Raciocínio Baseado em Casos e Redes Neurais. 


\section{Capítulo 2}

\section{Redes Neurais}

\subsection{Introdução}

O cérebro humano tem grande facilidade em resolver problemas para os quais computadores digitais com algoritmos convencionais não têm obtido o mesmo sucesso, como por exemplo, o reconhecimento de faces humanas. O cérebro "funciona" de uma maneira muito diferente das técnicas computacionais utilizadas convencionalmente [Beale 90]. Como resultado, muitos pesquisadores têm se dedicado ao estudo de sistemas neurais biológicos com o objetivo de projetar sistemas computacionais que funcionem de forma semelhante ao cérebro, adquirindo conhecimento através da experiência.

Redes Neurais (RN) são sistemas paralelos distribuídos, constituídos por um conjunto de unidades computacionais denominadas de neurônios. Os neurônios computam determinadas funções matemáticas e são interligados a outros neurônios através de conexões que geralmente estão associadas a pesos. Os pesos representam informações que serão utilizadas pela rede para solucionar problemas e servem para ponderar a entrada recebida por cada neurônio da rede. O funcionamento destas redes é inspirado numa estrutura física concebida pela natureza: o cérebro humano.

Reconhecimento de padrão é uma das principais aplicações de Redes Neurais. Nestas aplicações, o procedimento usual na solução de problemas passa inicialmente por uma fase de aprendizagem, no qual conjuntos de exemplos representativos das classes de padrões são apresentados à rede, que extrai automaticamente, através de um algoritmo de aprendizagem ou treinamento, as características necessárias para representar implicitamente os padrões. Estas características são 
utilizadas posteriormente pela rede, durante a sua fase de uso, para classificar outros padrões em função de seu grau de similaridade com as representações armazenadas na rede.

Computação Neural é uma das áreas de pesquisa que mais rapidamente tem se expandido, atraindo pesquisadores de uma grande variedade de disciplinas, como Engenharia, Física, Psicologia, Biologia, Medicina e outras, todas elas contribuindo significativamente para a área [Beale 90].

Provavelmente, Redes Neurais nunca serão capazes de competir com técnicas convencionais em tarefas de desempenho preciso e operações numéricas bem definidas, como inversão de matrizes ou cálculo de uma integral, por exemplo. Entretanto, problemas que envolvem ambigüidades, tal como reconhecimento de caracter manuscrito, parecem apropriados para serem solucionados por Redes Neurais [Widrow 94].

Este capítulo descreve, de um modo introdutório, tópicos básicos relacionados a Redes Neurais.

\subsection{Histórico}

Não são de hoje as idéias a respeito de máquinas que incorporam características neurais. Von Neumann, em "First draft of a report on the edvac" [von Neumann 45], fez várias correspondências entre os elementos de circuitos e os neurônios biológicos [Gurney]. Norbert Weiner [Heims 82], em 1942, formulou idéias sobre como os mecanismos biológicos podem ser tratados sob a perspectiva da engenharia e da matemática.

Em 1943, McCulloch e Pitts [McCulloch 43] publicaram o primeiro tratamento formal de Redes Neurais. O resultado deste artigo é a formalização de Redes Neurais através de modelos matemáticos e a prova teórica de que qualquer relação entrada-saída bem definida pode ser implementada utilizando uma Rede Neural, ou seja, qualquer função matemática ou lógica computável pode ser implementada utilizando unidades de "soma de produtos".

Uma das principais características de Redes Neurais é que elas podem aprender por meio de suas experiências em um ambiente de treinamento. Donald Hebb [Hebb 49], em 1949, mostrou como Redes Neurais poderiam ser treinadas. O peso associado a uma conexão poderia ser aumentado para refletir a correlação entre sua unidade de entrada e sua unidade de saída. 
Um dos mais significativos resultados apresentados foi o de Rosenblatt em 1957, quando ele desenvolveu o primeiro sistema prático, o perceptron, e provou que um simples procedimento de treinamento (a regra de treinamento do perceptron) convergia os pesos de uma rede para a solução de um problema se tal solução existisse. Muito do que ele descreveu pode ser encontrado em seu livro "Principles of Neurodynamics" [Rosenblatt 62].

O entusiasmo por Redes Neurais diminuiu em 1969 quando Minsky e Papert publicaram o livro "Perceptrons" [Minsky 69]. Os autores do livro mostraram que o perceptron não resolvia uma classe especial de problemas, aqueles que não são linearmente separáveis.

Nos anos 80, pesquisas realizadas por três pesquisadores fizeram ressurgir o interesse na área. Em 1982, John Hopfield [Hopfield 82] mostrou que uma rede altamente interconectada pode ser tratada como um sistema dinâmico. Kohonen [Kohonen 84], em 1984, estudou a capacidade auto-organizadora das redes. Rumelhart e McClelland [Rumelhart 86a, Rumelhart 86b, Rumelhart 86c], em 1986, propuseram um algoritmo de aprendizagem por retropropagação do erro para redes multi-camadas, conhecido como algoritmo Backpropagation. Embora este algoritmo já tivesse sido proposto anteriormente, antes de se tornar conhecido, por Bryson em 1969 [Bryson 69], Werbos em 1974 [Werbos 74], David Parker em 1985 [Parker 85] e por LeCun em 1986 [LeCun 86]. Com isto, foram superadas as limitações do perceptron de Rosenblatt.

Em 1987, dois pesquisadores, Carpenter e Grossberg [Carpenter 87a] desenvolveram a Teoria da Ressonância Adaptativa (Adaptative Resonance Theory ART) para solucionar um importante problema denominado dilema estabilidadeplasticidade [Grossberg 76a, Grossberg 76b].

No início da década de 90, as aplicações nos mais variados campos da indústria, comércio e ciência envolvendo Redes Neurais aumentaram consideravelmente. Reconhecimento de Padrão (detecção de fraudes em cartão de crédito [Hall 92, Hoffman 93, Shandle 93], reconhecimento de caracteres manuscritos [Schwartz 92]), Predição e Análise Financeira (aprovação de empréstimo, análise de marketing [Schwartz 92]), Controle e Otimização [Hammerstrom 93] são alguns dos problemas para os quais Redes Neurais têm sido utilizadas.

Uma das pesquisas mais recentes em Redes Neurais envolve sua utilização em sistemas híbridos, como por exemplo, Redes Neurais - Raciocínio Baseado em Casos (RBC) [Malek 95, Reategui 94, Reategui 95], Redes Neurais - Extração de Conhecimento [Fu 94, Milaré 97a, Pau 92], Redes Neurais - Algoritmos Genéticos [Mendes 97], Redes Neurais - Lógica Fuzzy [Goonatilake 95] e Redes Neurais - 
Estatística [Ripley 94]. No Capítulo 4, serão apresentados alguns estudos sobre a integração Redes Neurais - Raciocínio Baseado em Casos, que é o objetivo principal deste trabalho.

\subsection{Características de Redes Neurais}

Redes Neurais não são como programas seqüenciais que resolvem problemas executando instruções pré-definidas por um programador. O que elas fazem é aprender a resolver problemas por experiência, utilizando um estilo de processamento diferente. O resultado não é armazenado em uma determinada posição de memória específica, mas é dado pelo estado geral da rede. A informação está na forma como as unidades são interconectadas e nos pesos associados à cada conexão. Basicamente, uma Rede Neural é definida pelas características das unidades de processamento (neurônios ou nós), por sua topologia e pelo aprendizado. A seguir, estes aspectos serão analizados com mais detalhes.

\subsubsection{Unidades de Processamento}

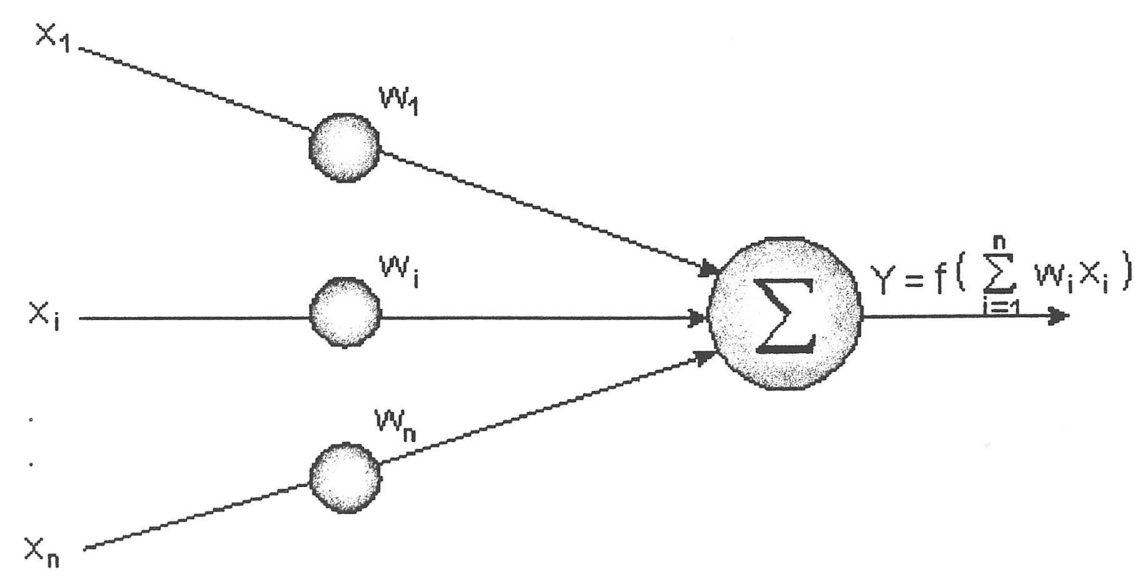

Figura 2.1: Unidade de processamento proposta por McCulloch e Pitts.

As unidades de processamento (neurônios) recebem entradas (sinais), $x_{i}$ ( $i=$ $1, \ldots, n)$, que podem vir de um ambiente externo à rede ou de outras unidades de processamento. As unidades computam uma função sobre o somatório de suas entradas ponderadas pelos respectivos pesos $\left(W_{i}\right)$, e o resultado é enviado para 
um ambiente externo ou para outras unidades de processamento. A Figura 2.1 mostra uma unidade de processamento proposta por McCulloch e Pitts em 1943.

\subsubsection{Topologia}

A topologia de uma Rede Neural informa como os seus neurônios estão interligados. As unidades de processamento podem estar distribuídas em várias camadas ou em uma única camada. Elas também podem estar conectadas a todas as outras unidades/entradas ou a um subconjunto das unidades/entradas da camada anterior. A melhor topologia para determinada rede depende do problema que se deseja resolver e da distribuição estatística dos dados disponíveis. A topologia também irá definir o número de camadas da rede e as funções implementáveis pela rede. Redes com uma única camada resolvem um número menor de funções do que redes multi-camadas.

As conexões, ou seja, as "ligações" entre duas unidades de processamento, podem estar dispostas de duas maneiras:

- Feed-forward: não há "loops", isto é, a saída de um neurônio não está ligada à entrada de um outro neurônio da mesma camada ou da camada anterior.

- Recorrente: há "loops" de conexões.

\subsubsection{Treinamento}

Uma das características mais importantes de Redes Neurais é sua capacidade de aprender. Uma Rede Neural está apta a resolver determinado problema para o qual foi treinada quando atingir uma solução generalizada.

Durante o treinamento, os pesos associados às conexões são calculados e modificados até a rede atingir uma configuração que produza as saídas desejadas, com uma margem de erro mínima, para as entradas apresentadas no treinamento.

O aprendizado pode ser supervisionado ou não supervisionado. No modo supervisionado são apresentados à rede, durante o treinamento, pares de padrões, no qual cada par é composto por uma entrada e sua saída desejada. No modo não supervisionado, a rede se organiza sozinha ("self-organising"), ou seja, ela procura regularidades nos padrões de entrada, não recebendo assim a saída desejada. 


\subsection{Principais Modelos}

\subsubsection{Perceptron}

O modelo básico de Redes Neurais foi proposto por Frank Rosenblatt em 1960, e recebeu o nome de perceptron. Em seu livro "Principles de Neurodynamics" [Rosenblatt 62], Rosenblatt descreve os perceptrons como redes simplificadas em que determinadas propriedades do sistema nervoso real são exageradas enquanto outras são ignoradas [Beale 90].

A regra de aprendizado do perceptron consiste em incrementar os pesos associados às entradas ativas quando se deseja que a saída seja ativa (saída igual a 1, por exemplo); e decrementá-los quando se deseja que a saída seja inativa (saída igual a 0 , por exemplo). Isto pode ser feito somando os valores de entrada aos respectivos pesos quando se deseja saída 1, e subtraindo os valores de entrada dos pesos quando se deseja saída 0 .

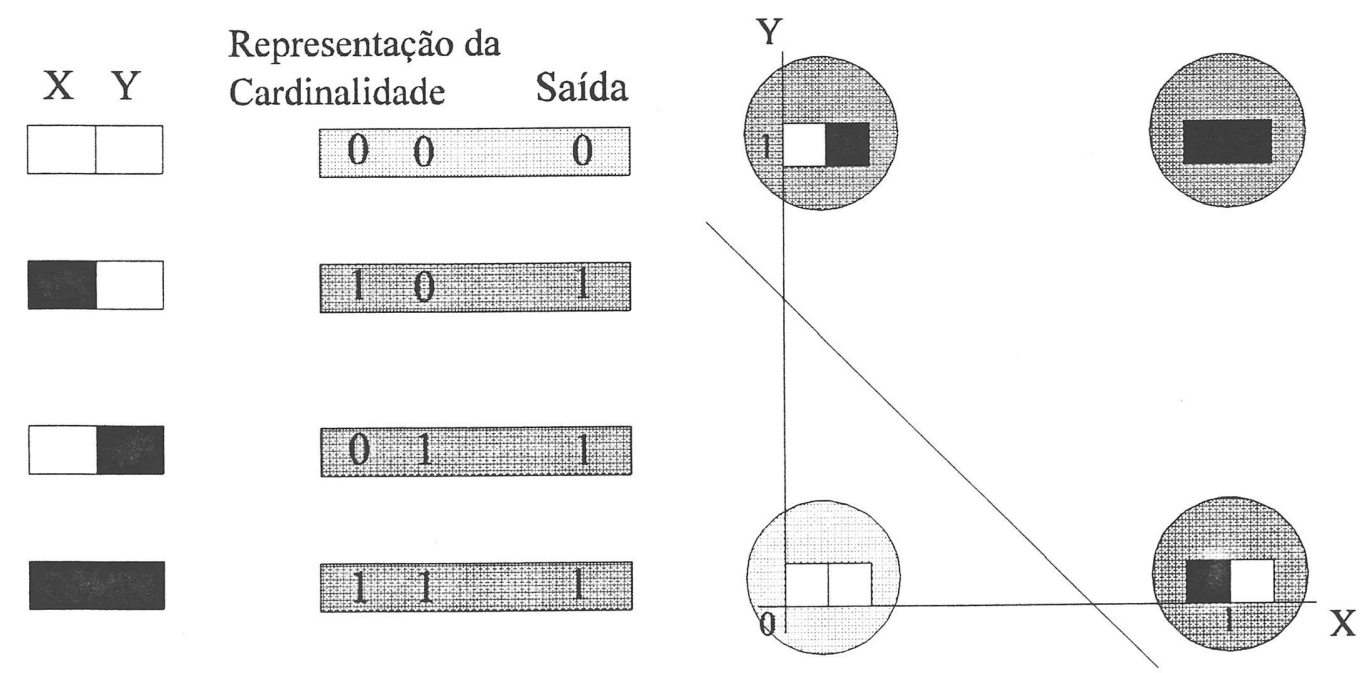

Figura 2.2: Exemplo da função lógica OR (adaptado de [Beale 90]).

O que o perceptron faz é encontrar um plano que separe os padrões em duas classes, ou seja, ele consegue separar qualquer conjunto de padrões linearmente separáveis. Perceptron de uma única camada não consegue resolver problemas que são linearmente inseparáveis. A Figura 2.2 mostra a função lógica OR, linearmente separável, e a Figura 2.3 mostra a função lógica XOR (ou-exclusivo), não linearmente separável. 

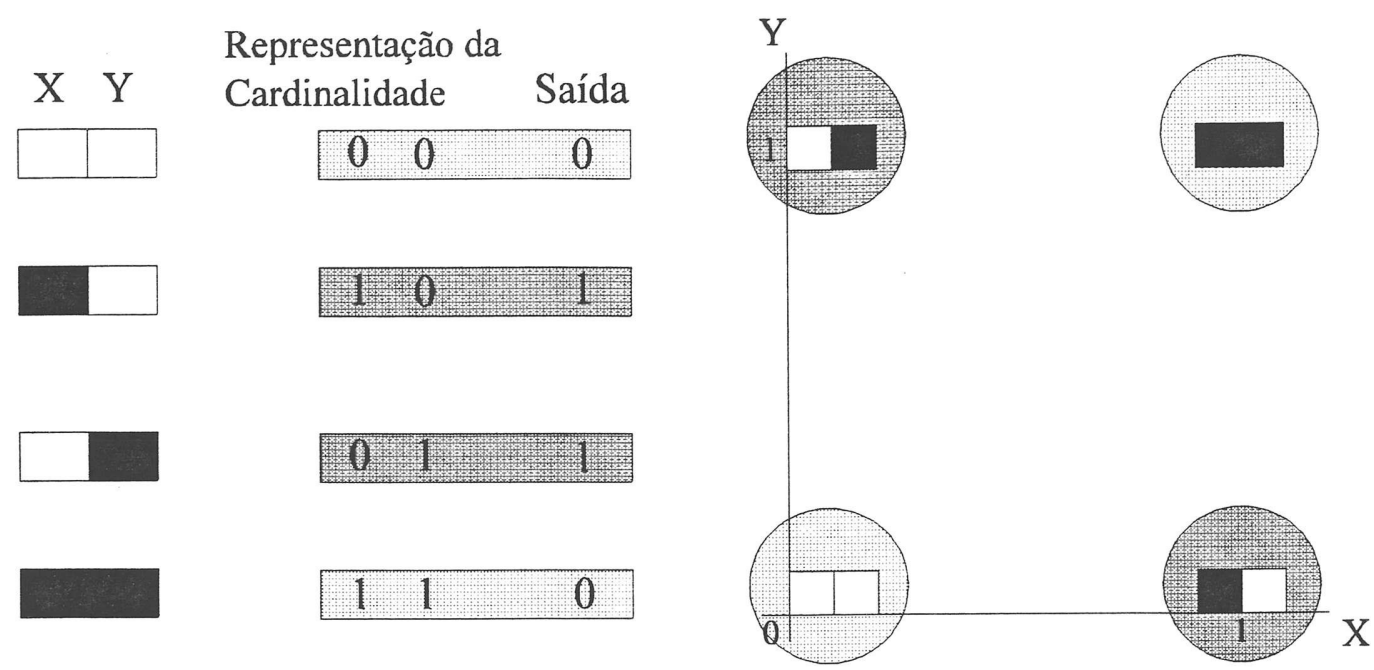

Figura 2.3: Exemplo da função lógica XOR (adaptado de [Beale 90]).

\subsubsection{Adaline}

Widrow e Hoff em [Widrow 60] sugeriram uma regra de aprendizado semelhante à regra de aprendizado do perceptron, conhecida como Regra Delta. A principal diferença é que enquanto o perceptron utiliza apenas a informação referente à saída da rede (resposta correta ou resposta incorreta), a Regra Delta calcula o erro baseado na diferença entre a saída produzida pela rede e a resposta desejada. O ajuste dos pesos é baseado neste erro. Os neurônios utilizados neste algoritmo de aprendizado foram chamados por Widrow de ADALINEs (Adaptive Linear Neurons). Como o perceptron, Adaline só resolve problemas linearmente separáveis.

\subsubsection{Perceptron Multi-Camadas}

Para resolver as limitações do perceptron de uma única camada, foi proposto um novo modelo, chamado perceptron multi-camadas, o qual mostrou-se capaz de resolver problemas linearmente inseparáveis. A Figura 2.4 mostra este novo modelo.

O modelo apresentado na Figura 2.4 possui três camadas: uma camada de entrada, uma camada intermediária e uma camada de saída. Com três camadas é possível resolver problemas mais complicados, como por exemplo, o da função XOR, mostrado na Figura 2.5. 


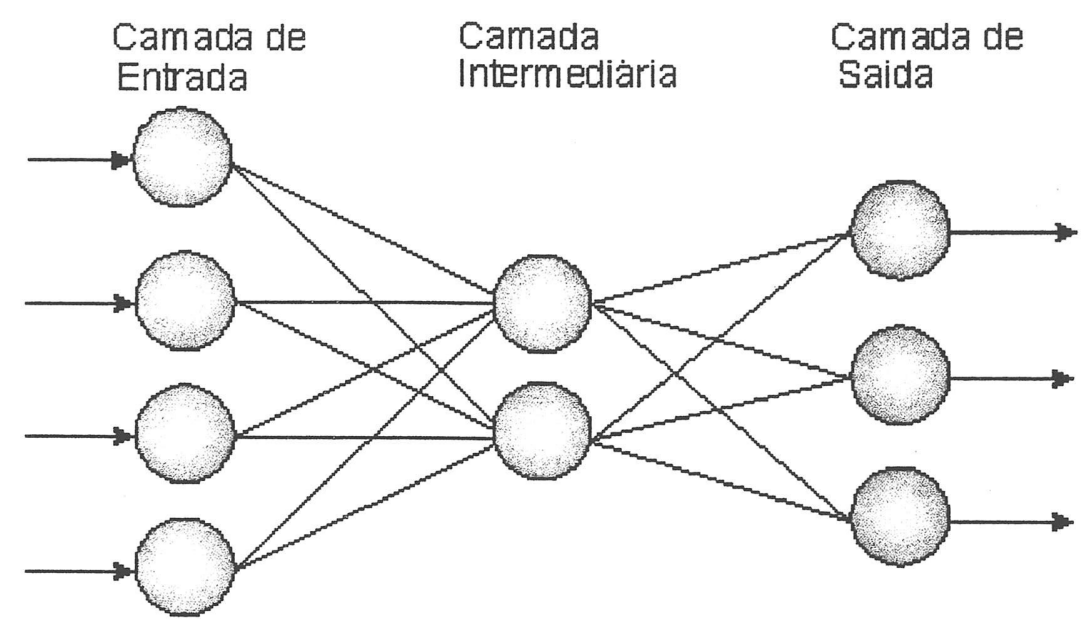

Figura 2.4: Perceptron Multi-Camadas.

A combinação de perceptrons realizada pelo perceptron multi-camadas resolve o problema da função XOR. Observando a Figura 2.5, verifica-se que o perceptron 1 detecta onde o padrão correspondente a $(0,1)$ está presente, e o perceptron 2 detecta onde o padrão $(1,0)$ está. Combinando estas duas funções, o perceptron 3 classifica a entrada corretamente.

A regra de aprendizado do perceptron multi-camadas é chamada de Regra Delta Generalizada ou Backpropagation, e tornou-se conhecida através de Rumelhart e McClelland, em [Rumelhart 86a, Rumelhart 86b, Rumelhart 86c], embora trabalhos anteriores já a tivessem mencionado.

Assim como no perceptron de uma camada, no perceptron multi-camadas um padrão é apresentado à rede, que calcula sua saída, compara-a com a saída desejada e então altera os pesos da rede para conseguir uma saída mais próxima a desejada no próximo ciclo. Ao apresentar um padrão de entrada a uma rede não treinada, esta produzirá qualquer saída. Como já foi comentado, é preciso definir uma função erro que represente a diferença entre a saída corrente da rede e a saída correta que se deseja produzir. Para que a rede aprenda os padrões é necessário que a saída da rede aproxime-se cada vez mais da saída desejada, isto é, que o valor da função erro seja continuamente reduzido. Isto é conseguido ajustando-se os pesos das conexões entre as unidades de processamento (neurônios). A Regra Delta Generalizada faz isto calculando o valor da função erro dos neurônios da camada de saída para uma entrada particular. Este erro é propagado para trás, de uma camada para sua camada anterior. Cada unidade de processamento da rede tem seus pesos ajustados, reduzindo-se assim o valor da função erro até um determinado limite, quando diz-se então que a rede aprendeu. 


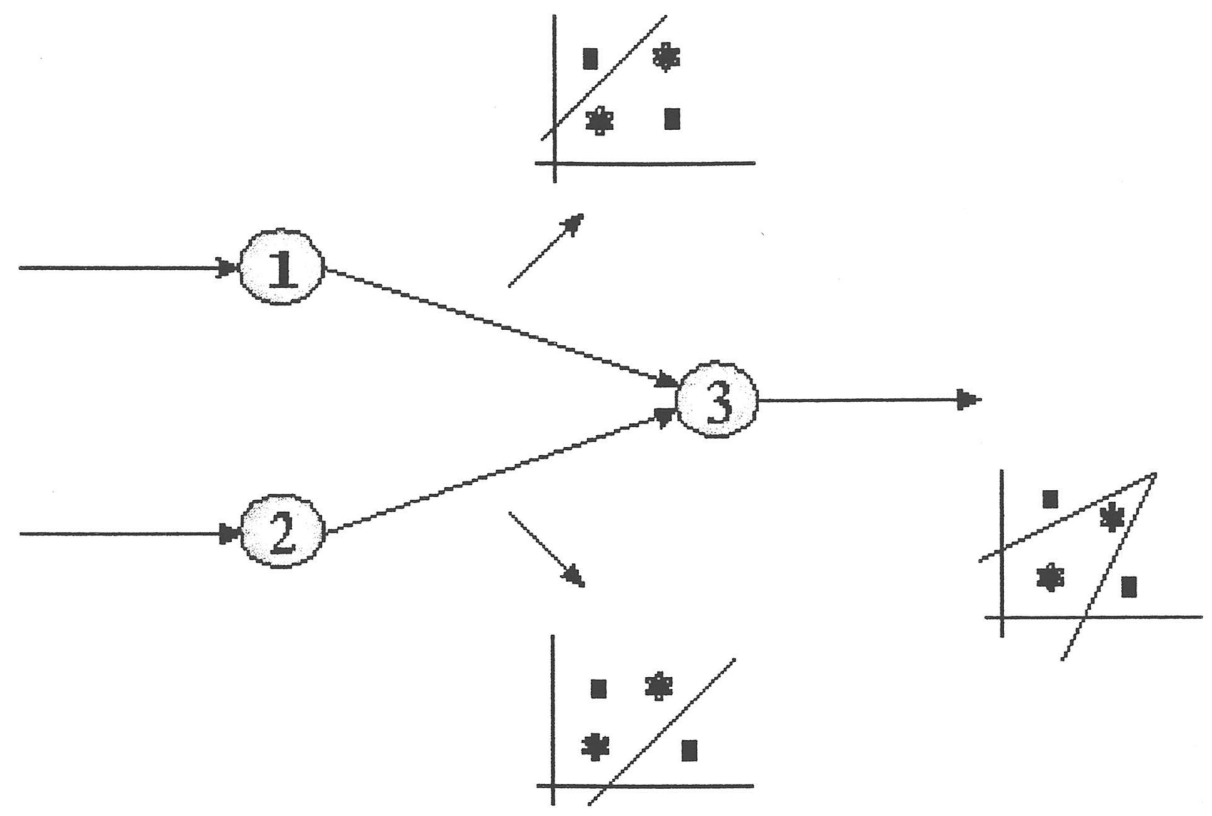

Figura 2.5: Resolução da Função XOR (adaptado de [Beale 90]).

\subsubsection{Rede de Hopfield}

John Hopfield [Hopfield 82] propôs um modelo de rede auto-associativa baseado em sistemas dinâmicos. Esta rede consiste de um número $N$ de neurônios, no qual cada neurônio está conectado com todos os outros, menos ele mesmo - veja Figura 2.6.

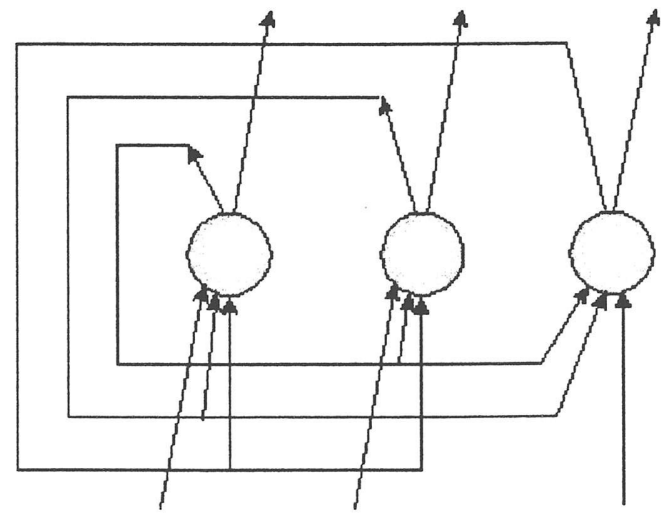

Figura 2.6: Rede de Hopfield.

As entradas da rede são apresentadas para todos os neurônios de uma vez, e consiste de um conjunto de valores bipolares iniciais, +1 ou -1 . A primeira saída obtida da rede serve como nova entrada, que produz nova saída, e assim 
sucessivamente até a rede convergir para uma solução estável, ou seja, até que não haja mudanças nos valores de saídas de ciclo para ciclo.

\subsubsection{Rede Auto-Organizável de Kohonen}

A Rede de Kohonen [Kohonen 84] utiliza aprendizado não supervisionado para modificar o estado interno da rede, modelando as características encontradas nos dados de treinamento.

Uma típica Rede de Kohonen é apresentada na Figura 2.7. Pode ser notada que a rede é bidimensional, com uma camada apenas. Os neurônios são dispostos em um plano. Todas as entradas estão conectadas com todos os neurônios e não há uma camada de saída separada, cada neurônio do plano é ele mesmo um neurônio de saída.

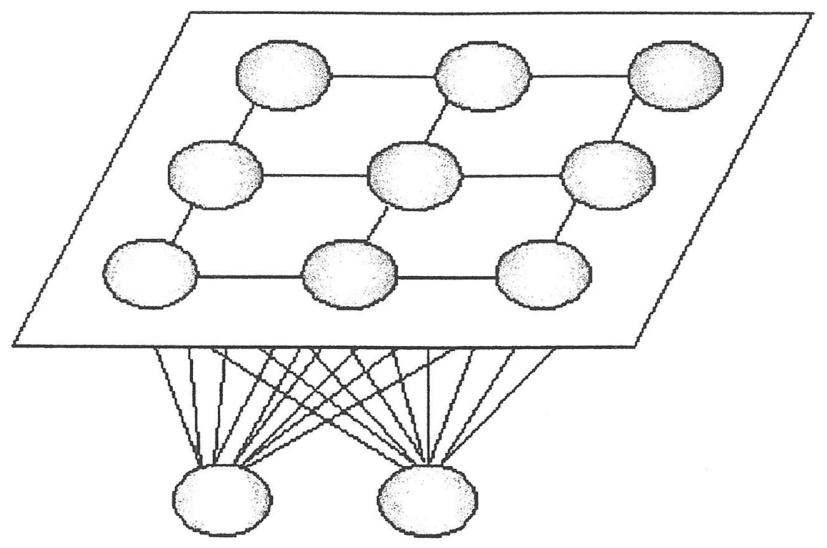

Figura 2.7: Rede de Kohonen.

\subsubsection{Rede ART}

A rede ART (Adaptive Resonance Theory) foi desenvolvida por Carpenter e Grossberg [Carpenter 87a]. Esta rede também agrupa padrões de entradas utilizando aprendizado não supervisionado. Quando um padrão é apresentado à rede, um neurônio da camada de saída (neurônio de cluster) apropriado é escolhido. Os pesos deste neurônio são ajustados para permitir que ele aprenda o padrão. Existem vários modelos ART. O Capítulo 3 descreve as redes ART, enfatizando a rede ART1, utilizada neste trabalho. 


\subsection{Conclusão}

Desde seu ressurgimento na década de 80, Redes Neurais têm provado ter potencial como uma tecnologia eficiente para resolver problemas que a computação tradicional não tem resolvido eficientemente, tais como reconhecimento de imagens, compreensão de linguagem escrita e falada, etc. Entretanto, esta abordagem não deve ser vista como uma proposta de substituição das abordagens convencionais, mas sim como uma tecnologia complementar que deve ser utilizada em conjunto com outras abordagens para atender cada vez mais e melhor as necessidades do usuário. 


\section{Capítulo 3}

\section{O Modelo ART}

\subsection{Introdução}

Uma das mais importantes características de Redes Neurais é sua habilidade de generalização, ou seja, produzir respostas para padrões de entrada que são similares, mas não idênticos, aos padrões apresentados à rede durante o seu treinamento [Fausett 94]. Quando uma rede multi-camadas é treinada com o algoritmo de aprendizado backpropagation, por exemplo, espera-se que ela forneça como resposta a classificação correta correspondente ao padrão de entrada, e que ela continue a responder corretamente para quaisquer padrões de entrada apresentado futuramente, isto se deve à sua capacidade de generalização.

Entretanto, o conhecimento a respeito de determinado domínio do mundo real pode se modificar ao longo do tempo. O mesmo acontece com os padrões de entrada de uma Rede Neural que podem modificar com o passar do tempo para acomodar mudanças ocorridas. Assim, para um número de aplicações, o desempenho da rede pode decair gradativamente com o tempo, uma vez que os pesos fixados na fase de treinamento não acompanham estas mudanças. Para adaptar novos padrões de entrada indefinidamente, um algoritmo de aprendizado de Redes Neurais deve ser plástico [Heins 95].

Uma alternativa para solucionar este problema seria retreinar a rede com os novos padrões de entrada. Entretanto, isto pode levar à perda de informações aprendidas anteriormente. Para preservar o conhecimento previamente aprendido, um algoritmo de aprendizado de Redes Neurais deve ser não somente plástico, mas também estável [Heins 95]. 
Uma outra solução seria retreinar a rede frequentemente com os novos e antigos padrões. Isto resolveria o problema, mas está longe de ser uma solução viável.

O conflito entre estabilidade e plasticidade é chamado dilema estabilidade-plasticidade [Grossberg 76a, Grossberg 76b], e envolve as seguintes questões:

- Como um sistema de aprendizado pode ser projetado para se adaptar indefinidamente em resposta a eventos significativos e ainda continuar indiferente a eventos irrelevantes?

- Como pode um sistema de aprendizado preservar seu conhecimento previamente aprendido enquanto continua a aprender conhecimentos novos?

- O que previne um novo conhecimento de se sobrepor a conhecimentos prévios?

Como foi dito antes, em aplicações do mundo real é comum ocorrerem mudanças inesperadas nos dados de entrada dos sistemas. É necessário então um modelo de Rede Neural incremental, no qual não seja preciso retreinar a rede quando mudanças nos padrões de entrada ocorrerem e que preserve o conhecimento aprendido previamente.

Uma família de Redes Neurais denominada de ART (Adaptive Resonance Theory) foi desenvolvida para solucionar o dilema estabilidade-plasticidade [Grossberg 76a, Grossberg 76b]. No decorrer deste capítulo, os principais aspectos da rede ART são descritos, enfatizando a rede ART1 [Carpenter 87a], primeiro modelo desenvolvido, que foi utilizado neste trabalho.

\subsection{Características Gerais de ART}

\subsubsection{Arquitetura Básica de ART}

A arquitetura básica de ART envolve duas camadas de neurônios. A camada de entrada, também conhecida como $F_{1}$, para o processamento dos dados de entrada; e a camada de saída, também conhecida como $F_{2}$, contendo os neurônios de cluster - ver Figura 3.1.

Estas duas camadas estão conectadas através de dois vetores de pesos. Um vetor de pesos feedforward, representado pela letra $B$, que assume valores reais e segue 


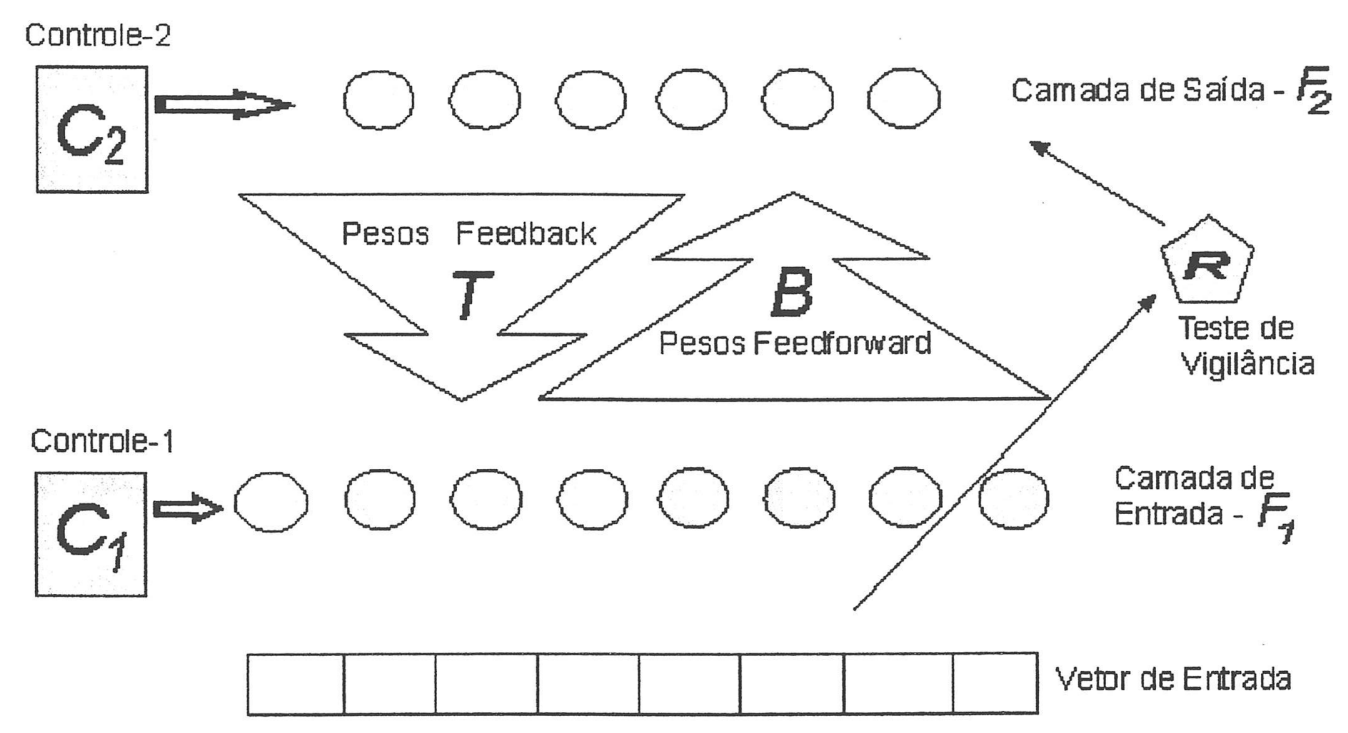

Figura 3.1: Arquitetura básica de ART.

da camada de entrada para a camada de saída; e outro vetor de pesos feedback, representado pela letra $T$, que assume valores binários e vai da camada de saída para a camada de entrada. Na Figura 3.2, o neurônio $X_{i}$ da camada de entrada está conectado ao neurônio $Y_{j}$ da camada de saída através do peso $b_{i j}$. Igualmente, o neurônio $Y_{j}$ da camada de saída está conectado ao neurônio $X_{i}$ da camada de entrada através do peso $t_{j i}$. Existem também pesos entre os neurônios da camada de saída que atuam como inibidores laterais.

Os pesos feedforward e feedback são também conhecidos como filtros adaptativos porque mudam dinamicamente para possibilitar o aprendizado de novos padrões de entrada. O vetor de pesos feedback associado a cada neurônio da camada de saída pode ser visto como um protótipo ou exemplar dos padrões que fazem parte do cluster representado por este neurônio.

Para cada camada da rede ART há uma unidade externa de controle. Estas unidades controlam o fluxo de dados através das camadas em cada fase de um ciclo de treinamento. Elas são representadas pelas letras $C_{1}$ e $C_{2}$ - ver Figura 3.1. $C_{1}$ determina o fluxo de dados para a camada de entrada. Assume valor 1 se uma entrada válida for apresentada à rede e valor 0 se algum neurônio da 


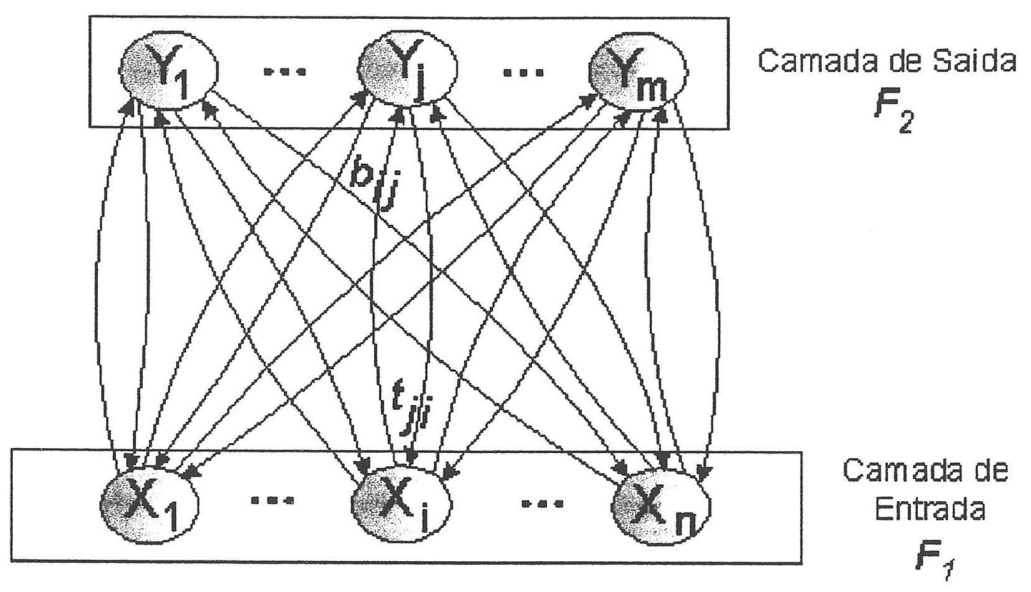

Figura 3.2: Os pesos na arquitetura de ART.

camada de saída está ativo. $C_{2}$ tem duas funções: determina o fluxo de dados para a camada de saída e habilita ou desabilita os neurônios da camada de saída. Assume valor 1 se uma entrada válida for apresentada à rede e 0 após desabilitar os neurônios da camada de saída e resetar seus estados de ativação para 0 .

Entre a camada de entrada e a camada de saída há também uma unidade de reset, representada pela letra $R$, que é responsável por comparar as entradas da rede com um threshold de vigilância $(\rho)$. Este threshold de vigilância determina se uma nova classe de padrões (cluster) poderá ser criada para um padrão de entrada.

\subsubsection{Treinamento}

O algoritmo de aprendizado da rede ART é não supervisionado e está apto a entrar no modo de treinamento a qualquer momento, possibilitando que a rede incorpore conhecimento novo. Esta característica resolve o problema plasticidadeestabilidade comentado anteriormente.

Há dois tipos de treinamento para ART: aprendizado rápido e aprendizado lento. No aprendizado rápido os pesos feedforward são setados para seus valores ótimos em poucos ciclos, geralmente em apenas um ciclo de treinamento. No aprendizado 
lento os pesos são ajustados lentamente em vários ciclos de treinamento, significando que maior atenção será dada para encontrar as características relevantes dos padrões de entradas para determinar sua classificação.

A rede ART é muito sensível a variações em seus parâmetros durante o treinamento. O parâmetro mais crítico é o threshold de vigilância $(\rho)$ que controla a resolução do processo de classificação. Se $\rho$ assume um valor baixo $(<0.4)$, a resolução do processo de classificação será baixa, criando poucas classes. Se $\rho$ for setado com um valor alto, pequenas variações nos padrões de entrada levarão a criação de novas classes.

\subsection{Aprendizado em ART1}

O processo de aprendizado em ART1 envolve algumas fases, tais como: inicialização dos parâmetros e pesos da rede, reconhecimento, comparação e busca. Cada uma destas fases será descrita a seguir.

\subsubsection{Inicialização}

$\mathrm{Na}$ fase de inicialização, devem ser atribuídos valores aos elementos dos vetores de pesos $B$ e $T$. Todos os pesos feedback $(T)$ são inicializados com o valor 1 binário, indicando que todo neurônio da camada de saída está inicialmente conectado a todo neurônio de entrada através de uma conexão feedback. Os valores iniciais do vetor de pesos feedforward $(B)$ são determinados pela Equação 3.1:

$$
b_{i j}=\frac{1}{1+n}
$$

no qual $n$ é o número de neurônios de entrada da rede.

O threshold de vigilância $(\rho)$ é também inicializado, assumindo um valor dentro do intervalo $0<\rho<1$.

\subsubsection{Reconhecimento}

Cada neurônio da camada de entrada recebe sinais de três fontes: um sinal do vetor de entrada, um sinal feedback da camada de saída e um sinal da unidade 
de Controle-1 $\left(C_{1}\right)$. Um neurônio da camada de entrada somente será ativado se receber pelo menos dois sinais excitatórios, caso contrário, a ativação não ocorre. Esta regra é denominada regra dois-terços $(2 / 3)$.

$\mathrm{Na}$ fase de reconhecimento, o vetor de entrada é enviado à camada de entrada, onde será aplicada a regra $2 / 3$. Em seguida, o vetor de entrada é comparado com todos os vetores de pesos feedforward, $B$, para encontrar o melhor matching. Esta comparação é realizada calculando-se o produto interno entre o vetor de entrada resultante da aplicação da regra $2 / 3$ e o vetor de peso feedforward de cada neurônio da camada de saída, dada pela Equação 3.2.

$$
y_{j}=\sum_{i} b_{i j} x_{i}
$$

onde $y_{j}$ é o somatório do produto correspondente ao neurônio de saída $j$, entre cada componente $b_{i j}$ do vetor de pesos $B$ e cada componente $x_{i}$ do vetor entrada.

O neurônio da camada de saída cujo produto apresenta o maior valor é selecionado como provável cluster para armazenar o novo padrão. Este neurônio envia à camada de entrada seu protótipo ou exemplar, ou seja, seu vetor de pesos $T$. A inibição lateral faz com que somente o neurônio vencedor da camada de saída fique ativo.

\subsubsection{Comparação}

Conforme descrito anteriormente, cada neurônio da camada de entrada recebe três sinais: do vetor de entrada; do vetor do exemplar do neurônio de saída selecionado, vindo da fase de reconhecimento; e da unidade de Controle- $1\left(C_{1}\right)$, que neste instante é zero porque um neurônio foi ativado na fase de reconhecimento. A regra 2/3 é aplicada novamente resultando na ativação ou não de cada neurônio da camada de entrada.

Como o sinal da unidade de Controle-1 é zero, há uma operação $A N D$ entre o vetor exemplar do neurônio selecionado e o vetor de entrada para produzir um novo vetor, chamado de vetor de comparação. Este vetor é enviado para o mecanismo de reset juntamente com o vetor de entrada.

O mecanismo de reset é responsável por testar a similaridade entre o vetor de entrada e o vetor de comparação. O teste é feito calculando a razão $P$, através da Equação 3.3, entre o número de uns de ambos os vetores, de entrada e de comparação, e comparando o resultado desta razão com o threshold de vigilância 
$(\rho)$. Se $P$ for maior que $\rho$, então o neurônio da camada de saída ativado incluirá o vetor de entrada em seu cluster, caso contrário, outro neurônio da camada de saída deverá ser encontrado para representar o vetor de entrada e a rede entra na fase de busca.

$$
P=\frac{\left\|\sum x_{i} t_{i j}\right\|}{\left\|\sum x_{i}\right\|}
$$

\subsubsection{Busca}

Durante esta fase, a rede tenta encontrar um outro neurônio da camada de saída para representar o vetor de entrada corrente.

O neurônio da camada de saída rejeitado na fase de comparação anterior é impossibilitado de competir para representar o padrão de entrada corrente. Para isto, o neurônio vencedor é desabilitado, setando seu valor de saída para 0 , indicando que ele não poderá mais ser selecionado para o padrão de entrada corrente. $\mathrm{O}$ vetor de entrada é reapresentado e a rede entra novamente na fase de comparação, que termina com o teste no mecanismo de reset para determinar a similaridade entre o novo exemplar escolhido e o vetor de entrada corrente. Este processo é repetido, desabilitando neurônios da camada de saída, até encontrar um neurônio de saída que melhor "case" com o vetor de entrada corrente, dentro dos limites do threshold de vigilância $(\rho)$. Se nenhum neurônio de saída for encontrado, o vetor de entrada é então considerado de uma classe desconhecida e será alocado um neurônio de saída "livre" (que não esteja associado ainda a nenhum cluster) para representá-lo.

\subsection{Exemplo}

Um exemplo será descrito para melhor compreensão do funcionamento do aprendizado da rede ART1. Neste exemplo, há três neurônios na camada de entrada e inicialmente um neurônio na camada de saída. $C_{1}$ e $C_{2}$ são inicializados com zero, o parâmetro de vigilância é inicializado para 0.8 , os pesos feedback com 1 e os pesos feedforward de acordo com a Equação 3.1.

$\mathrm{O}$ vetor de entrada $S$ é aplicado à camada de entrada $\left(F_{1}\right)$ - ver Figura 3.3. A regra $2 / 3$ determina a resposta da camada entrada para o padrão de entrada. Neste ponto, a camada de entrada recebe dois sinais excitatórios; um sinal do 


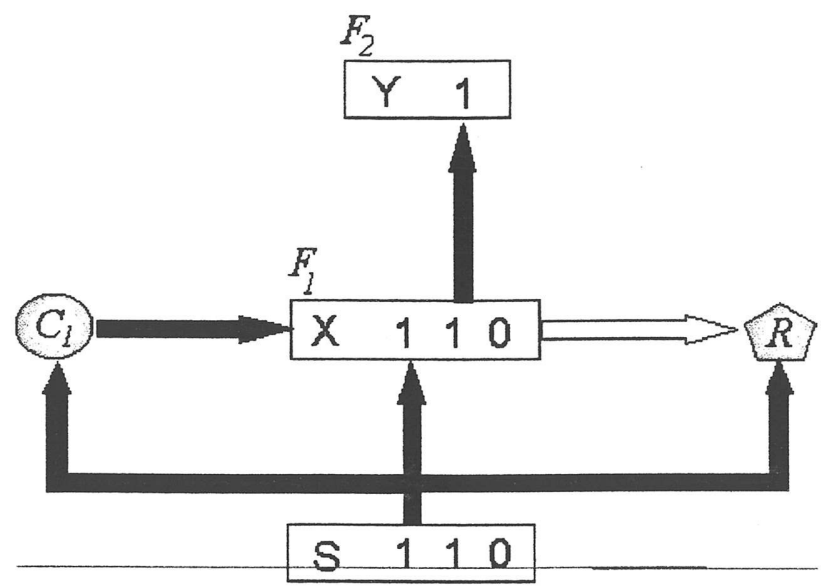

Figura 3.3: Passo 1.

vetor de entrada $S$ e um sinal da unidade de Controle-1 $\left(C_{1}\right)$, significando que há uma entrada válida para a rede. Os sinais excitatórios correspondem a 1 binário e os sinais inibitórios correspondem a 0 binário. Na Tabela 3.1 é mostrado o resultado, vetor $X$, do efeito destes sinais após aplicar a regra $2 / 3$.

O vetor $X$ é comparado com os pesos feedforward de cada neurônio da camada de saída. Isto é feito calculando o produto interno entre estes vetores utilizando a Equação 3.2.

\begin{tabular}{||c|c|c|}
\hline \hline Entrada $(S)$ & $C_{1}$ & Resultado $(X)$ \\
\hline 1 & 1 & 1 \\
\hline 1 & 1 & 1 \\
\hline 0 & 1 & 0 \\
\hline
\end{tabular}

Tabela 3.1: Resultado da primeira aplicação da regra 2/3.

O neurônio selecionado como vencedor (neurônio com maior produto interno) envia seu exemplar armazenado para a camada de entrada $\left(F_{1}\right)$ e inibe $C_{1}$, setando seu valor para 0 . A camada de entrada recebe três sinais: do vetor de entrada, do neurônio vencedor da camada de saída e de $C_{1}$ - ver Figura 3.4. O resultado depois de aplicada a regra $2 / 3$ pode ser visto na Tabela 3.2.

O vetor de comparação $X^{*}$ e o vetor de entrada $S$ são enviados ao mecanismo de reset para o teste de vigilância. A razão $(P)$ entre estes dois vetores é calculada pela Equação 3.3, sendo neste caso igual a 1, porque os vetores são idênticos. 


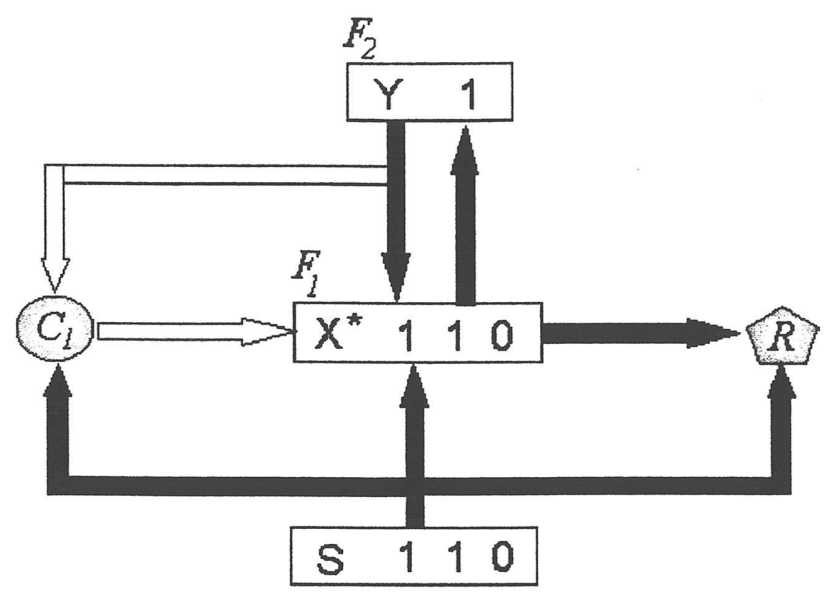

Figura 3.4: Passo 2.

\begin{tabular}{||c|c|c|c|}
\hline \hline Entrada $(S)$ & Pesos Feedback & $C_{1}$ & Resultado $\left(X^{*}\right)$ \\
\hline 1 & 1 & 0 & 1 \\
\hline 1 & 1 & 0 & 1 \\
\hline 0 & 1 & 0 & 0 \\
\hline
\end{tabular}

Tabela 3.2: Resultado da segunda aplicação da regra 2/3.

Esta razão é comparada ao threshold de vigilância $(\rho)$, sendo aqui maior que 0.8 , então o vetor de entrada foi classificado corretamente. Em seguida, os vetores de pesos do neurônio vencedor são ajustados para incorporar as características do vetor de entrada corrente. Isto é feito pelas Equações 3.4 e 3.5.

$$
\begin{gathered}
T_{i j(\text { novo })}=T_{i j(\text { velho })} \wedge X_{i} \\
B_{i j(\text { novo })}=\frac{L * X_{i}}{L-1+\sum T_{i j(v e l h o)} \wedge X_{i}}
\end{gathered}
$$

onde $\wedge$ é o operador lógico AND e $L$ é um parâmetro $(L>1)$ utilizado na atualização dos pesos feedforward.

Quando a razão $(P)$ é menor que $\rho, R$ dispara e inibe o neurônio ativado da camada de saída - ver Figura 3.5. O padrão de entrada será atribuído a outro neurônio da camada de saída. Após a aplicação do próximo vetor de entrada à 
rede, a unidade de Controle-2 $\left(C_{2}\right)$ habilita todos os neurônios inibidos da camada de saída para que eles voltem a competir entre si.

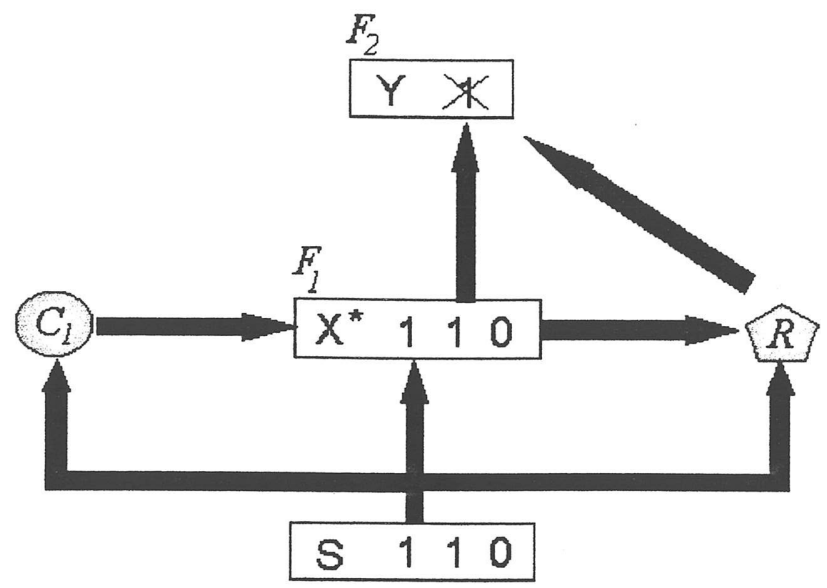

Figura 3.5: Passo 3.

O algoritmo de aprendizado lento do modelo ART1 é sumarizado a seguir.

1. Inicializar pesos e parâmetros

2. Repita

2.1 Para cada padrão de treinamento $S$

2.2 Definir neurônio vencedor

2.3 Comparar prototipo do vencedor com a entrada

2.4 Se comparação > threshold de vigilância

Então atualizar os pesos do neurônio vencedor

Senão desabilitar neurônio

Se ainda existir neurônio não analisado

Então voltar a 2.2

Senão alocar novo neurônio ao padrão de entrada

Ate conjunto de prototipos não mudar

\subsection{Modelos ART}

Desde o surgimento da Teoria da Ressonância Adaptativa várias outras redes baseadas em ART foram desenvolvidas. O primeiro modelo da família ART a ser desenvolvida foi a rede ART1 [Carpenter 87a]. Esta rede responde à sequências arbitrárias de padrões de entrada binários. 
Entretanto, vários problemas do mundo real utilizam dados analógicos. Em vista disto, foi desenvolvida a rede ART2 [Carpenter 87b]. Esta rede reconhece categorias (classes) em resposta a sequências arbitrárias de padrões de entrada analógicos (valores contínuos), tão bem como para sequências de padrões binários. A diferença entre ART1 e ART2 está na camada $F_{1}$, que precisa ser mais complexa para realizar o pré-processamento necessário para acomodar os padrões de entrada de valores contínuos.

A rede ARTMAP [Carpenter 91b] é outra rede baseada na rede ART que realiza aprendizado incremental supervisionado para reconhecer categorias em resposta a vetores de entrada apresentados à rede. Esta classe é composta por duas redes $\operatorname{ART1}\left(A R T_{a}\right.$ e $\left.A R T_{b}\right)$. Durante o treinamento, o módulo $A R T_{a}$ recebe um padrão de entrada $a^{(p)}$ e o módulo $A R T_{b}$ recebe um padrão de entrada $b^{(p)}$ que é a predição correta de $a^{(p)}$, ou seja, $b^{(p)}$ é a resposta desejada do padrão $a^{(p)}$. Estes dois módulos são conectados através de um mapeamento entre as camadas de saída $\left(F_{2}\right)$ de $A R T_{a}$ e $A R T_{b}$.

A primeira rede ARTMAP foi utilizada para classificar entradas que eram vetores de valores binários representando a presença ou ausência de cada característica. Uma rede ARTMAP mais geral foi então projetada para aprender a classificar entradas que eram vetores de valores fuzzy entre 0 e 1 indicando o nível de presença de cada característica apresentada. Esta generalização é realizada substituindo os módulos de ART1 de ARTMAP por módulos de outra rede baseada em ART, a rede Fuzzy ART [Carpenter 91c]. A nova rede é conhecida como rede Fuzzy ARTMAP [Carpenter 92].

Existem outras variações, não tão conhecidas, baseadas na rede ART: CALM [Murre 89], ART3 [Carpenter 90], ART2a [Carpenter 91a], SMART [Bartfai 94] e HART [Bartfai 95].

\subsection{Conclusão}

O modelo ART foi proposto para resolver o dilema estabilidade-plasticidade [Grossberg 76b]. Esta rede inclui um padrão de entrada em um cluster selecionado somente se este padrão é suficientemente semelhante a este cluster. O padrão de entrada e os padrões armazenados no cluster selecionado são ditos "ressoar" quando eles são suficientemente semelhantes. Este modelo é capaz de entrar no modo de aprendizado a qualquer momento para aprender novos conhecimentos sem perda de conhecimentos previamente aprendidos. 
Foram desenvolvidas várias redes baseadas no modelo ART. ART1 [Carpenter 87a], primeira classe a ser projeta, aceita como entrada para a rede somente vetores binários e é a rede utilizada neste trabalho. 


\section{Capítulo 4}

\section{Raciocínio Baseado em Casos: uma Visão Geral}

\subsection{Introdução}

Geralmente, quando alguém deseja consultar com algum médico, são escolhidos aqueles mais velhos e com mais experiência. Isto ocorre porque as pessoas sentem-se mais seguras em tratar-se com médicos que já viram e trataram muitos pacientes com a mesma doença, do que com médicos récem formados, que provavelmente são mais atualizados com relação à diagnósticos e tratamentos, mas que não têm muita experiência prática. Para muitos pacientes, é mais importante em um médico sua experiência prática do que seus conhecimentos gerais.

Raciocínio Baseado em Casos (RBC) é um paradigma de Inteligência Artificial que resolve problemas utilizando analogia. Analogia significa lembrança, e no contexto de RBC, significa lembrar de experiências prévias, também denominadas de casos, para resolver problemas correntes [Aamodt 94, Barletta 91], ver Figura 4.1. A utilização de $\mathrm{RBC}$ na resolução de problemas envolve adaptar soluções antigas para atender novas necessidades, usar casos antigos para explicar novas situações, utilizar experiências passadas para criticar novas soluções ou raciocionar a partir de precedentes para interpretar uma situação semelhante [Kolodner 93].

RBC é a essência de como o ser humano raciocina no seu dia a dia. As pessoas a todo momento estão utilizando suas próprias experiências, ou a dos outros, para obterem informações que as ajudem a resolver um determinado problema.

A seguir é apresentado um exemplo encontrado em [Kolodner 92] que utiliza RBC 


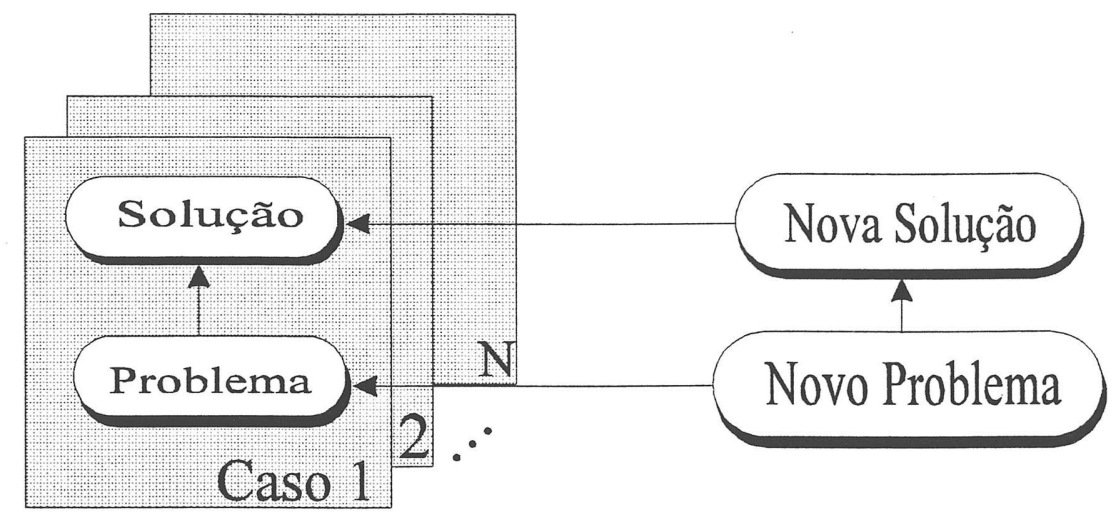

Figura 4.1: Idéia básica para resolver problemas.

para ajudar um psiquiatra a diagnosticar a doença de uma paciente.

Um psiquiatra analisa uma paciente que exibe sinais claros de depressão. A paciente conta ao médico, entre outras coisas que, recentemente, teve um problema de estômago que os médicos não encontraram a causa orgânica. Enquanto que na psiquiatria não é dado muita importância às reclamações aparentemente sem ligação com o caso, o doutor está relembrando um caso anterior em que ele diagnosticou um paciente com depressão que também queixou-se de um conjunto de problemas físicos que não poderiam ser explicados organicamente. Somente depois de perceber que deveria também ter dado àquelas queixas maior atenção, ele faz então o diagnóstico de Distúrbios Somáticos Associados à Depressão. Por ter se lembrado do caso anterior, a hipótese do psiquiatra de que esta paciente também deve ter Distúrbios Somáticos Associados à Depressão prosseguiu com a investigação do diagnóstico apropriado.

No exemplo acima, o médico utiliza o diagnóstico de um caso anterior para formar uma hipótese sobre o diagnóstico do novo caso. Esta hipótese faz com que o doutor tenha um raciocínio mais curto (um atalho), e também o alerta para evitar um equívoco ocorrido anteriormente. Mais ainda, o caso anterior faz com 
que ele focalize sua atenção em aspectos do caso que ele normalmente não teria considerado.

Este capítulo apresenta, de uma forma genérica, o funcionamento e os mecanismos de um sistema de $\mathrm{RBC}$, os estilos existentes de sistemas de $\mathrm{RBC}$, as suas origens e história e ainda como Redes Neurais têm sido integradas a estes sistemas.

\subsection{Origens e História de RBC}

Acredita-se que os trabalhos de Roger Schank em [Schank 77], sobre raciocínio e aprendizado baseados em memória e os modelos descritos por ele com tais características para construção de sistemas computacionais, preconizaram o paradigma de RBC. Entretanto, o que de fato marcou o início de RBC, foi a publicação do trabalho de Roger Schank em 1982 sobre memória dinâmica, intitulado Dynamic Memory: A Theory of Reminding and Learning in Computers and People [Schank 82]. Suas idéias foram expandidas por seus alunos, principalmente por Janet Kolodner que desenvolveu, na Universidade de Yale, em 1983, o primeiro sistema que realmente pôde ser chamado de resolvedor baseado em casos. $\mathrm{O}$ sistema em questão foi chamado CYRUS [Kolodner 83a, Kolodner 83b]. O modelo de memória baseado em casos desenvolvido no sistema CYRUS serviu de base para outros sistemas de RBC em diversas áreas, tais como MEDIATOR [Simpson 85] (na área de mediação), PERSUADER [Sycara 88] (na área de persuasão), CHEF [Hammond 89] (na área de culinária), JULIA [Hinrichs 92] (na área de culinária) e CASEY [Koton 89] (na área da medicina).

Outros trabalhos envolvendo modelos diferentes foram desenvolvidos por Bruce Porter e seu grupo na Universidade do Texas [Porter 86]. Os frutos destes trabalhos foram os sistemas PROTOS [Bareiss 89] (na área da medicina) e o sistema GREBE [Branting 91] (no domínio das leis). Edwina Rissland e seu grupo da Universidade de Massachusetts, também contribuíram significativamente para a pesquisa de RBC, desenvolvendo o sistema HYPO [Ashley 91] (sobre leis) e mais tarde, CABARET [Skalak 92] (ferramenta/shell). Phyllis Koton do MIT, estudou a utilização de RBC para otimizar o desempenho de um sistema baseado em conhecimento da área médica, resultando no sistema CASEY [Koton 89].

Entre os primeiros resultados de pesquisa sobre RBC, que começou um pouco tarde na Europa, está o sistema REFINER desenvolvido por Sunil Sharma [Sharma 88] que foi resultado do estudo sobre o uso de casos para refinamento de bases de conhecimento; e o trabalho de Michael Richter e Klaus Dieter Althoff [Althoff 89] sobre diagnóstico técnico. Enric Plaza e Ramon López desenvolve- 
ram um sistema aprendiz para diagnóstico médico [Plaza 90] e Beatrice López [López 90] estudou os métodos baseados em casos para raciocínio estratégico. O sistema PATDEX de Richter e Weiss [Richter 91] e outros sistemas e métodos vieram em seguida.

Atualmente, as pesquisas envolvendo $\mathrm{RBC}$ têm se expandido para vários outros centros. Não só pesquisadores de países europeus e norte-americanos estão trabalhando com o paradigma de RBC, mas estudiosos do Japão e de alguns países asiáticos (por exemplo a India [Venkatamaran 93]), também se mostram interessados nos diversos domínios de aplicação deste paradigma.

\subsection{Como Funciona um Sistema de RBC}

Dada a descrição de um novo caso como entrada para um sistema de RBC, este deve buscar, em sua memória de casos, um caso armazenado que se pareça com a descrição de entrada. A seguir, o sistema deve adaptar, ou seja, modificar as partes do caso recuperado que não se ajustam à descrição de entrada. Como resultado desta adaptação tem-se uma solução para o problema proposto e um novo caso que poderá ser adicionado à memória de casos do sistema. Em geral, sistemas de RBC estão relacionados aos seguintes processos:

- Representação de Casos

- Indexação de Casos

- Armazenamento e Recuperação de Casos

- Adaptação de Casos

- Avaliação e Reparo de Casos

Um conjunto de soluções coerentes para estes processos constitui um sistema típico de RBC. A Figura 4.2 mostra como estes processos estão conectados em um sistema de RBC típico. A seguir, cada um destes cinco processos serão analizados.

\subsubsection{Representação de Casos}

Um resolvedor baseado em casos é fortemente dependente da estrutura e conteúdo armazenado em sua coleção de casos já que, para resolver um novo problema, 


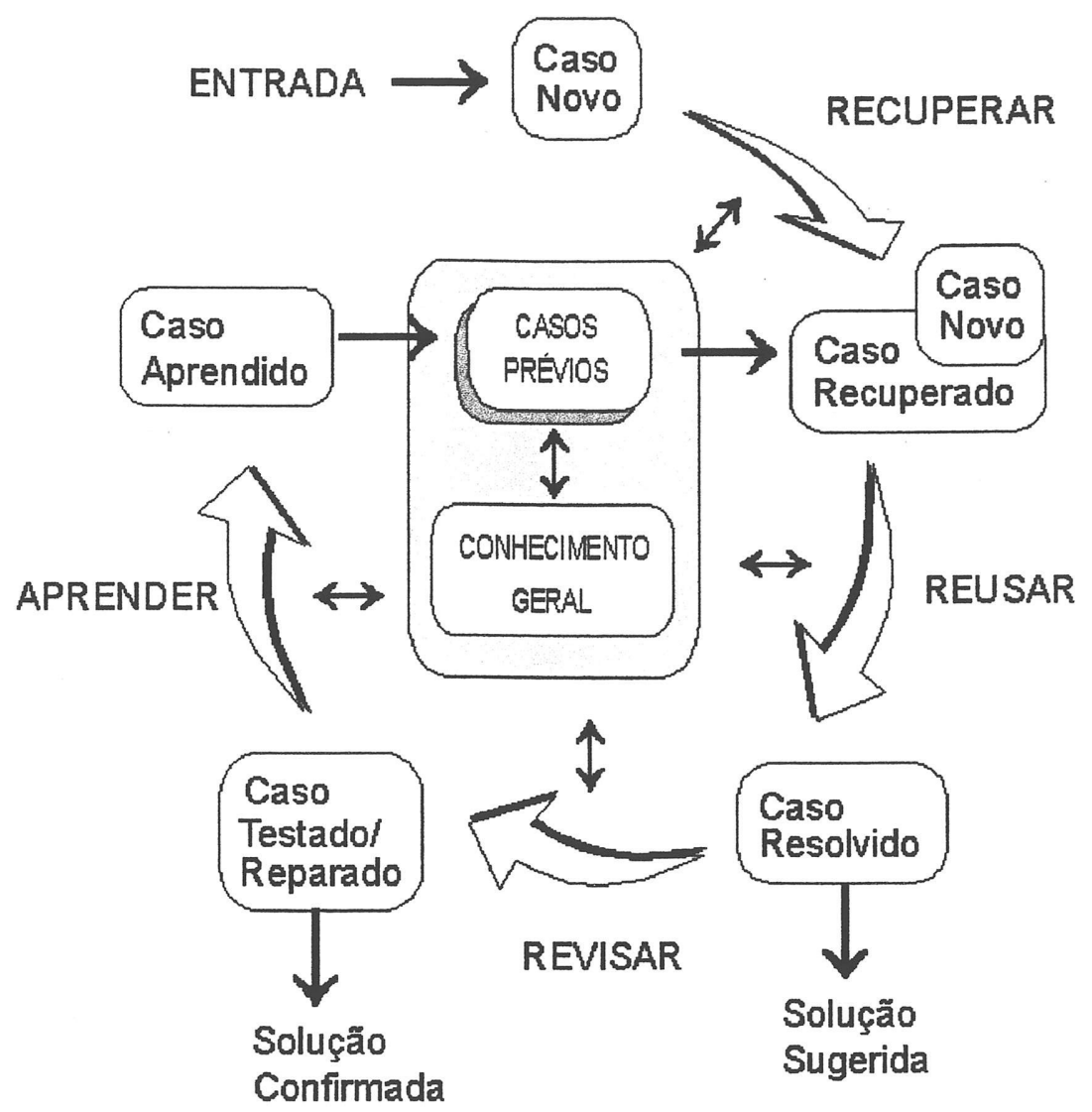

Figura 4.2: Ciclo de um sistema de RBC (adaptado de [Aamodt 94]).

deve-se "lembrar" de uma experiência anterior conveniente. Os processos de busca e matching de casos precisam ser eficientes e executados em um tempo razoável. O problema de representação de casos em $\mathrm{RBC}$ pode ser abordado através da:

1. Definição do conteúdo que será armazenado.

2. Determinação das características mais relevantes de cada caso.

3. Busca de uma estrutura apropriada para descrever estas características.

O primeiro problema, definir o conteúdo que será armazenado, significa escolher o que representar dos casos. Geralmente, e para a maioria dos casos, este conteúdo pode ser dividido em três partes: 
- Descrição situacional do problema, que descreve o estado do mundo quando o caso aconteceu e qual o problema a ser solucionado naquele momento.

- Solução do problema, que descreve a solução encontrada para o problema em questão e, às vezes, o procedimento utilizado na sua resolução.

- Resultado, que descreve o estado resultante do mundo quando a solução foi utilizada.

Dependendo das informações armazenadas nestas três partes, pode-se utilizar o caso para diferentes propósitos. Assim, se são armazenadas características que descrevem o problema e sua solução, será possível usá-las para propor a solução para um novo problema. Se o procedimento utilizado na solução de um problema é armazenado, é possível utilizar o método antigo de resolução para derivar uma nova solução.

O segundo problema é determinar as características mais relevantes de cada caso. Esta é a principal tarefa de Engenharia do Conhecimento em sistemas de RBC. Embora possa parecer trivial, identificar características em casos, principalmente do mundo real, não é simples. Definir a terminologia do domínio e selecionar os exemplos representativos de resolução dos problemas, também são tratados aqui.

O terceiro problema envolve encontrar a estrutura apropriada para descrever as caracteríticas relevantes dos casos. Há várias estruturas propostas para representação de conhecimento. Entre elas, pode-se citar Redes Semânticas e Memória Episódica [Slade 91], Roteiro (script), Cena e MOP (Memory Organization Packet) [Schank 89].

\subsubsection{Indexação de Casos}

O poder de um sistema de RBC está em sua habilidade em recuperar com rapidez e segurança casos relevantes de sua memória (Base de Casos). O objetivo do processo de indexação é fornecer condições para que um caso semelhante possa ser selecionado e recuperado quando solicitado. Para recuperar um caso, é preciso que ele esteja endereçado apropriadamente na memória, ou seja, é preciso designar um rótulo (índice) para que o caso possa ser recuperado.

Os tipos de indexação mais utilizados são: 
- Indexação pelo vizinho mais próximo: baseia-se na soma dos pesos das características do caso de entrada que combinam com o caso recuperado. Por exemplo, se houver um caso que combine nove características com o caso de entrada e outro caso que combine somente cinco, o sistema, dependendo do peso associado a cada característica, escolheria o primeiro. Um problema que ocorre com este tipo de indexação é quanto ao peso de determinadas características, que só terão o mesmo valor para casos muito semelhantes. Cada caso deverá ter seu próprio conjunto de pesos de características para determinar sua relevância para um novo problema.

- Indexação indutiva: determina-se indutivamente quais as características mais importantes para vários casos e a memória de casos é organizada com base nas características encontradas. É possível determinar automaticamente as melhores características de um caso. Este tipo de indexação é aplicado quando a meta a ser recuperada é bem definida e quando existirem exemplos suficientes para cada tipo de meta.

- Indexação baseada em conhecimento: utiliza o conhecimento existente na literatura para cada caso e determina quais características são importantes para recuperá-los. Esta abordagem é preferível quando há conhecimento disponível e representável. Muitas vezes, é dificíl codificar informação explanatória para realizar a indexação baseada em conhecimento para um conjunto abrangente de possíveis casos de entrada.

\subsubsection{Armazenamento e Recuperação de Casos}

Uma vez que os casos estejam representados e indexados, eles devem ser organizados (armazenados) em uma estrutura eficiente para serem recuperados posteriormente. Isto envolve dois processos: armazenamento e recuperação de casos.

No processo de armazenamento, um novo caso é armazenado apropriadamente na memória de casos para poder então ser utilizado no futuro. Dado um problema, o sistema de RBC recupera de sua memória de casos o caso mais semelhante ao problema. Na maioria das vezes, o sistema tem que modificar algumas partes do caso recuperado para obter a solução para o problema proposto, porque dificilmente se terá casos totalmente iguais. Depois de adaptar o caso antigo, tem-se um novo caso (caso antigo, modificado para atender as necessidades de um novo problema) que poderá ser armazenado ou não na memória de casos do sistema. A decisão de armazenar um novo caso pode ser feita indiscriminadamente pelo sistema, ou pelo engenheiro do conhecimento, que decidirá quais novos casos serão armazenados. Segundo [Barletta 91] quando se adiciona um novo caso na 
memória de casos, está se adicionando novo conhecimento ao sistema, ou seja, o sistema está aprendendo.

Em geral, o processo de recuperação de um caso ou conjunto de casos, consiste de dois subprocessos:

- Acessar casos anteriores: recupera um conjunto de possíveis candidatos a serem escolhidos através de algoritmos de busca. Este conjunto é formado por casos que podem fornecer soluções relevantes sobre o problema proposto. Este subprocesso é conhecido como matching parcial.

- Selecionar: escolhe o caso ou os casos mais promissores do conjunto de casos previamente acessados utilizando uma função de maching.

O Capítulo 5 descreve a relação existente entre os processos de recuperação e aprendizado de casos.

\subsubsection{Adaptação de Casos}

Como foi descrito na resolução de problemas utilizando RBC, soluções antigas são usadas como "inspiração" para resolver novos problemas. Como novos problemas raramente se encaixam exatamente em algum caso antigo, as soluções antigas devem ser modificadas para atender às novas situações. Este processo de modificação chama-se adaptação.

Existem algumas regras de adaptação que podem ser utilizadas pelos sistemas de RBC. Estas regras, aplicadas ao caso recuperado, o transformam em um novo caso que se assemelha ao problema proposto. A dificuldade em se definir uma estratégia para adaptação de casos é que este processo tende a ser um problema específico e dependente do domínio. Por exemplo, a estratégia de adaptação necessária para um problema de projeto, deve ser diferente da estratégia de adaptação necessária para um problema de diagnóstico.

\subsubsection{Avaliação e Reparo de Casos}

Após a obtenção de uma nova solução, esta deve ser testada em um processo chamado de avaliação, que tem por objetivo verificar se a nova solução resolve ou não o problema proposto. Esta avaliação pode ser feita baseada nos efeitos 
causados quando aplicada ao mundo real, ou baseada na simulação mental ou real, ou ainda baseada no contexto de casos anteriores.

Se a solução obtida falha, deve-se identificar as causas da falha, identificando por exemplo, as diferenças entre o que era esperado e o que de fato aconteceu. E, finalmente, o processo de reparo, como o próprio nome diz, repara a solução proposta tornando-a apta a resolver corretamente o problema proposto.

\subsection{Estilos de Raciocínio Baseado em Casos}

Há dois estilos de Raciocínio Baseado em Casos:

- Resolvedor de Problemas.

- Interpretativo.

No primeiro estilo, resolvedor de problemas, soluções antigas são utilizadas para resolver novos problemas. As soluções antigas contribuem tanto sugerindo soluções que já foram aplicadas em problemas parecidos, como alertando para possíveis falhas que possam ocorrer. Este estilo é útil para tarefas que envolvem solucionar problemas da área de planejamento, diagnóstico e projeto. O sistema CHEF [Hammond 89] é um exemplo de sistema de RBC resolvedor de problemas da área de planejamento (culinária). Ele cria novas receitas tendo por base receitas já conhecidas. Para criar, por exemplo, uma receita utilizando carne bovina e brócolis, o sistema lembra de uma receita que utiliza carne de frango e ervilhas e a adapta. O primeiro passo na fase de adaptação é substituir a carne de frango por carne bovina, e a ervilha por brócolis. Em seguida, se a carne bovina não possui osso, o passo desossar é eliminado e se o brócolis requer um tempo maior para cozinhar, então o tempo de cozimento é mudado no passo que o legume é cozido.

No segundo estilo, o interpretativo, as novas situações são avaliadas no contexto das situações antigas. Este estilo é utilizado em classificação de situações, avaliação de uma solução, argumentação, justificação de uma solução, interpretação e projeção dos efeitos de uma decisão. As pessoas utilizam muito RBC interpretativo no seu quotidiano. Por exemplo, quando uma criança diz: "Mas vocêe deixou ela (sua irmã) fazer isto!", ela está usando um caso para justificar seu argumento; ou quando um advogado utiliza vários casos antigos para justificar um argumento de um novo caso, ele utiliza raciocínio baseado em casos estilo interpretativo. 


\subsection{Raciocínio Baseado em Casos e Redes Neu- rais}

Raciocínio Baseado em Casos e Redes Neurais têm sido combinados em algumas pesquisas recentes [Malek 95, Reategui 95, Reategui 94, Krovvidy 93, Petridis 93, Sase 93, Wendel 93, Barnden 92]. Esta integração pode ser realizada pela divisão das tarefas entre Raciocínio Baseado em Casos e Redes Neurais ou pelo desenvolvimento de arquiteturas inteligentes que combinam as características de Raciocínio Baseado em Casos e Redes Neurais.

Em algumas propostas para a integração de Raciocínio Baseado em Casos e Redes Neurais, Redes Neurais têm sido utilizadas principalmente para fazer o matching entre os casos e para recuperação dos casos. Outras propostas envolvem Redes Neurais no processo de recuperação, extraindo conhecimento para suportar o raciocínio.

Utilizar Redes Neurais no processo de indexação dos casos tem a desvantagem da necessidade de retreinar a rede sempre quando um novo caso é adicionado à Base de Casos. Entretanto, aprendizado incremental pode ser utilizado eliminando a necessidade de retreinar a rede. Outra alternativa é utilizar Redes Neurais para aquisição de casos. Nesta situação, a rede pode ser treinada com exemplos representativos do problema que se deseja resolver. Regras poderiam ser extraídas de Redes Neurais para construir a Base de Casos. A seguir, alguns trabalhos no qual Raciocínio Baseado em Casos e Redes Neurais são combinados serão apresentados.

\subsubsection{Combinações Prévias}

Krovvidy and Wee [Krovvidy 93] apresentam um sistema de tratamento de esgoto utilizando Raciocínio Baseado em Casos e Redes Neurais. Antes de ser lançado ao meio ambiente o lixo (esgoto) doméstico e proveniente das indústrias precisa ser tratado. Para isto é necessŕio reduzir as concentrações de um ou mais contaminantes deste lixo através da aplicação de processos sequenciais de tratamento. No modelo desenvolvido neste trabalho o componente referente a $\mathrm{RBC}$ fornece um estado inicial de uma solução para uma rede de Hopfield que é então utilizada para sugerir um sequência ótima de processos para tratamento da água. Quando uma nova sequência de processos é necessária para o tratamento de determinada água, as concentrações dos elementos contaminadores desta água são utilizados para indexar uma solução de um tratamento que teve sucesso utilizando concen- 
trações semelhantes.

Malek, em [Malek 95], propõe um sistema simples de indexação, no qual foi construído na memória uma hierarquia de casos em dois níveis. O nível mais baixo contém casos organizados dentro de grupos de casos semelhantes. O nível mais alto contém protótipos, cada um representando um grupo de casos. Este nível é usado para indexar o sistema. A construção dos protótipos é feita utilizando uma Rede Neural incremental baseada em protótipos. Este sistema de indexação baseado em protótipo foi comparado com outros dois métodos de indexação indutiva, o C4.5 e o ID5R, e mostrou-se melhor em registrar generalizações corretas. Outras vantagens são a diminuição do tempo de recuperação, devido a um número menor de protótipos; a simplificação do aprendizado de novos casos, já que para isto é preciso somente modificar uma unidade neural (protótipo).

No trabalho descrito em [Reategui 95], Redes Neurais são utilizadas para aprender padrões de similaridade entre os casos de um sistema de RBC para avaliação psicológica de candidatos à transplante de coração. $O$ conhecimento implícito armazenado na rede é extraído e interpretado simbolicamente. Depois ele é armazenado em uma estrutura chamada de descritores de diagnósticos que é utilizada para guiar o processo de raciocínio no sistema de RBC. Foram coletados gráficos mostrando a relevância de possíveis combinações de características, dados pelo especialista, para cada diagnóstico considerado. Estes gráficos foram comparados com o conhecimento armazenado nos descritores e verificou-se que o tipo de informação armazanada nos descritores é muitas vezes diferente do conhecimento representado nos gráficos dos especialistas, mas quando utilizados na prática, a representação dada pelo especialista tem menor taxa de classificação correta que a representação dada pelo computador.

Em outro trabalho [Reategui 94], Redes Neurais e CBR são combinados em um sistema para classificação de transações de cartão de crédito. Enquanto o sistema de RBC utiliza casos específicos para determinar quando uma transação poderia ser admitida ou recusada, a Rede Neural reconhece padrões gerais de comportamento para o uso correto ou incorreto de cartões de crédito e utiliza este conhecimento na classificação da tarefa. Um protótipo deste sistema híbrido foi implementado e seu desempenho mostrou-se satisfatório; $89 \%$ dos casos foram classificados corretamente, $5.3 \%$ incorretamente e em $5.7 \%$ o sistema não determinou a classificação. 


\subsection{Conclusão}

RBC é um paradigma poderoso de IA, baseado essencialmente em uma idéia muito simples, utilizada todos os dias pelas pessoas: resolver problemas utilizando experiências anteriores. Apesar de ser simples e rápida, e muitas vezes utilizada inconscientemente pelas pessoas, quando se tenta implementá-la, encontram-se algumas dificuldades, como por exemplo, representação das experiências no computador, determinação do índice dos casos, além de muitas outras vistas no decorrer deste capítulo. RBC é uma das áreas de pesquisa e desenvolvimento que mais rapidamente tem crescido. Algumas de suas vantagens são:

- Permite propor soluções para os problemas rapidamente.

- Possibilita propor soluções para domínios ainda não estudados vastamente.

- Alerta para possíveis problemas que ocorreram na solução de determinados casos no passado e que poderão ocorrer novamente.

- Focaliza a atenção para partes importantes do problema, apontando suas características mais relevantes. 


\section{Capítulo 5}

\section{Recuperar e Aprender Casos}

\subsection{Introdução}

Talvez o mais importante processo na construção de um sistema de Raciocínio Baseado em Casos seja a recuperação apropriada dos casos. É por este processo que se mede o desempenho do sistema. Portanto, a fase de recuperação de casos da Base de Casos deve ser eficiente, embora não seja trivial realizá-la.

Quando se fala em recuperar casos há muitas questões que devem ser mencionadas, pois estão diretamente envolvidas nesta etapa. Ao ser apresentada a descrição de um caso novo a um sistema de Raciocínio Baseado em Casos, a Base de Casos deve ser percorrida para encontrar casos com algum potencial para "casar" com a descrição dada. Isto é feito por algoritmos de recuperação. Depois que vários casos forem identificados por estes algoritmos é preciso comparar suas características às da descrição do caso novo e determinar quão semelhante é cada caso identificado com o caso novo. Isto é realizado por procedimentos de matching, que são importantes para determinar a pontencialidade de cada caso previamente identificado pelos algoritmos de recuperação em relação ao caso novo.

Os índices de um caso têm papel importante, pois auxiliam a destacar as características relevantes para se determinar a similaridade entre os casos, ou seja, é através deles que os algoritmos de recuperação e os procedimentos de matching realizam suas tarefas. Os algoritmos de recuperação estão também fortemente ligados às estruturas que deverão percorrer e à organização destas estruturas na Base de Casos. Uma estrutura de lista, por exemplo, é percorrida diferentemente de uma estrutura de árvore. 
Por último, há também o problema em se manter a Base de Casos, ou seja, incorporar casos novos ao sistema. A dificuldade e custo desta operação depende da estrutura para armazenar os casos, da organização destes casos na Base de Casos e dos índices utilizados para recuperá-los. Quanto mais simples são resolvidos estes problemas, mais barato e mais fácil é incorporar um caso novo à Base de Casos.

A seguir serão descritas algumas possibilidades de organização dos casos na Base de Casos, os algoritmos correspondentes para recuperá-los, o uso dos índices e também a dificuldade em se incorporar um caso novo em cada situação.

\subsection{Algoritmos de Recuperação}

A comunidade envolvida nesta área de pesquisa, Raciocínio Baseado em Casos, dedica grande parte de seus esforços em melhorar ou tornar o processo de recuperação dos casos mais eficiente. Existem vários algoritmos para a recuperação dos casos [Kolodner 93]. Cada um destes algoritmos está associado com a organização e tipo das estruturas que compõem a Base de Casos. A organização dos casos na Base de Casos e os algoritmos correspondentes mais utilizados para recuperá-los são:

- Memória Plana - Busca Serial/Busca Paralela

- Redes de Características Compartilhadas - Busca em Largura

- Redes de Discriminação por Prioridade - Busca em Profundidade

- Redes de Discriminação Reduntante - Busca em Largura

- Memória Hierárquica - Busca Paralela

Para ilustrar as estruturas de organização de uma Base de Casos e os algoritmos de recuperação correspondentes apresentados no decorrer deste capítulo, serão utilizados casos do sistema MEDIATOR [Kolodner 89], descritos a seguir.

Chocolate: Duas crianças querem a mesma barra de chocolate. Sua mãe tem que dividir o chocolate ao meio. Cada criança pega uma metade do chocolate e come a sua metade. (disputa física) 
Laranja1: Duas irmãs adolescentes querem a mesma laranja. Sua mãe tem que cortá-la ao meio. Cada adolescente pega uma metade da laranja. Uma das irmãs come sua metade da fruta; a outra utiliza a casca de sua metade para cozinhar. A mãe percebe que sua solução falhou e considera o que ela deve ter feito de errado. Ela percebe que não entendeu o objetivo da segunda filha e por engano assumiu que esta queria comer a laranja, quando de fato esta queria usar a casca para cozinhar. (disputa física).

Laranja2: Duas irmãs adolescentes querem a mesma laranja. Uma quer comer a fruta, outra quer utilizar a casca para cozinhar. Sua mãe deixa a segunda extrair a casca da laranja e então entrega a fruta para a primeira irmã. Ambas as irmãs estão satisfeitas. (disputa física)

Coréia: Direitistas e esquerdistas querem o controle da Coréia. Depois de considerável combate sem vencedor, é decidido dividir o país entre dois grupos: os direitistas ficam com o sul, e o esquerdistas com o norte. (disputa física)

Panamá: Estados Unidos e Panamá querem o controle do Canal do Panamá; os Estados Unidos por razões de segurança, e o Panamá porque o canal está em seu território. Depois de negociações é decidido que o Panamá pode ficar com a terra e direitos econômicos porque o canal está em seu território, mas os Estados Unidos ficam com os direitos de segurança porque eles pagaram para a construção do canal e querem que este seja aberto. (disputa política)

\subsubsection{Memória Plana - Busca Serial/Busca Paralela}

$\mathrm{Na}$ organização dos casos utilizando memória plana, os casos são armazenados sequencialmente em uma simples lista, registro ou arquivo. Eles podem ser recuperados utilizando busca serial ou busca paralela. Estes dois tipos de busca envolvidos na organização sequencial dos casos serão descritos a seguir.

Busca Serial Para recuperação de casos organizados sequencialmente na memória utilizando busca serial basta aplicar uma função de matching, sequencialmente, em cada caso e, posterior seleção dos mais similares. A Figura 5.1 mostra casos organizados sequencialmente em uma estrutura de lista, por exemplo.

A vantagem em ter os casos organizados sequencialmente é que toda a Base de Casos é percorrida. A recuperação somente irá depender da eficiência e qualidade 


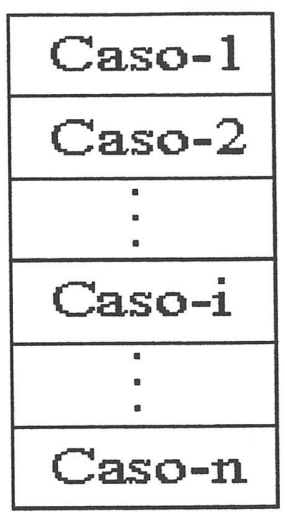

Figura 5.1: Casos sequencialmente organizados.

da função de matching utilizada. Se as heurísticas da função de matching são boas, então o melhor caso provavelmente sempre será recuperado. Outra vantagem é a facilidade e custo baixo da adição de novos casos à Base de Casos. A desvantagem é o tempo necessário para recuperação quando a Base de Casos é grande, o que acaba tornando este método caro.

Busca Paralela Quando a Base de Casos for muito grande, a utilização de arquiteturas paralelas pode melhorar muito o tempo de processamento de um sistema de Raciocínio Baseado em Casos. Uma maneira para utilizar uma máquina paralela, SIMD (Simgle Instruction, Multiple Data), como uma Base de Casos é armazenar casos como vetores de características, alocando cada vetor dentro de um processador [Kolodner 88]. A recuperação é feita emparelhando o caso novo com todos os vetores de características em paralelo. A Figura 5.2 ilustra este método. Os índices aqui funcionam para definir o que priorizar no matching, não para guiar a busca.

As vantagens do esquema de recuperação paralela são a facilidade e rapidez do algoritmo de recuperação, uma vez que o matching e a recuperação acontecem em apenas um passo, e a facilidade em adicionar um caso novo porque não há necessidade em organizar os casos. A desvantagem é o custo do hardware necessário à este tipo de busca. 


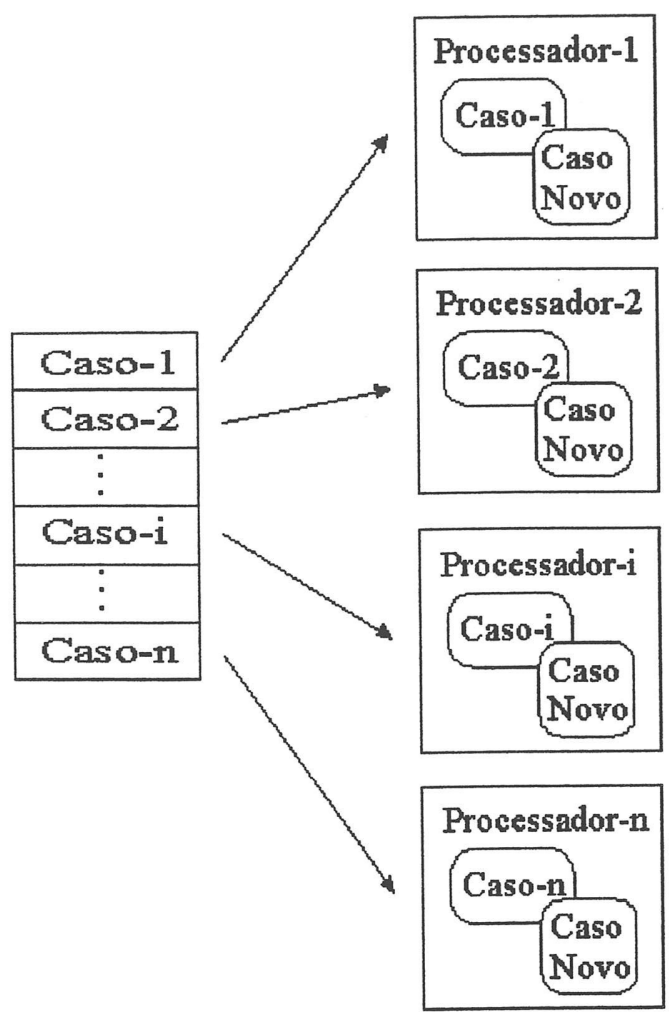

Figura 5.2: Cada caso é designado à um processador.

\subsubsection{Rede de Características Compartilhadas - Busca em Largura}

Quando a Base de Casos é muito grande, é necessário organizar os casos hierarquicamente, de modo que apenas alguns pequenos subconjuntos precisem ser considerados durante a recuperação. Se casos semelhantes estiverem agrupados, somente os casos dos subconjuntos mais parecidos com o novo caso serão considerados na escolha do melhor caso. Existem vários algoritmos para formação de subconjuntos ou clusters [Lopes 95]. As hierarquias são formadas quando clusters são divididos em subclusters e assim por diante.

Redes de características compartilhadas agrupam casos que compartilham muitas características. Cada nó interno desta rede representa características compartilhadas de casos que estão localizados abaixo deste nó. Os nós terminais correspondem aos casos. A Figura 5.3 mostra um exemplo de casos do sistema MEDIATOR [Kolodner 89], descritos anteriormente, organizados em uma rede de características compartilhadas. 
Para recuperar um caso desta rede realiza-se uma busca em largura. O caso novo é comparado ao conteúdo dos nós de níveis superiores. O melhor matching é escolhido. Se o nó visitado é um caso, este caso é retornado. Caso contrário, se for um nó interno, a busca continua em seus descendentes até um caso ser retornado.

Construir esta estrutura requer um algoritmo de agrupamento para agrupar os casos dentro de cada cluster. O nó representando cada cluster se ramifica. Estas ramificações correspondem a especializações dos casos representados por este cluster. Em seguida, o algoritmo de agrupamento é aplicado novamente nos casos de cada cluster para criar mais ramificações inferiores.

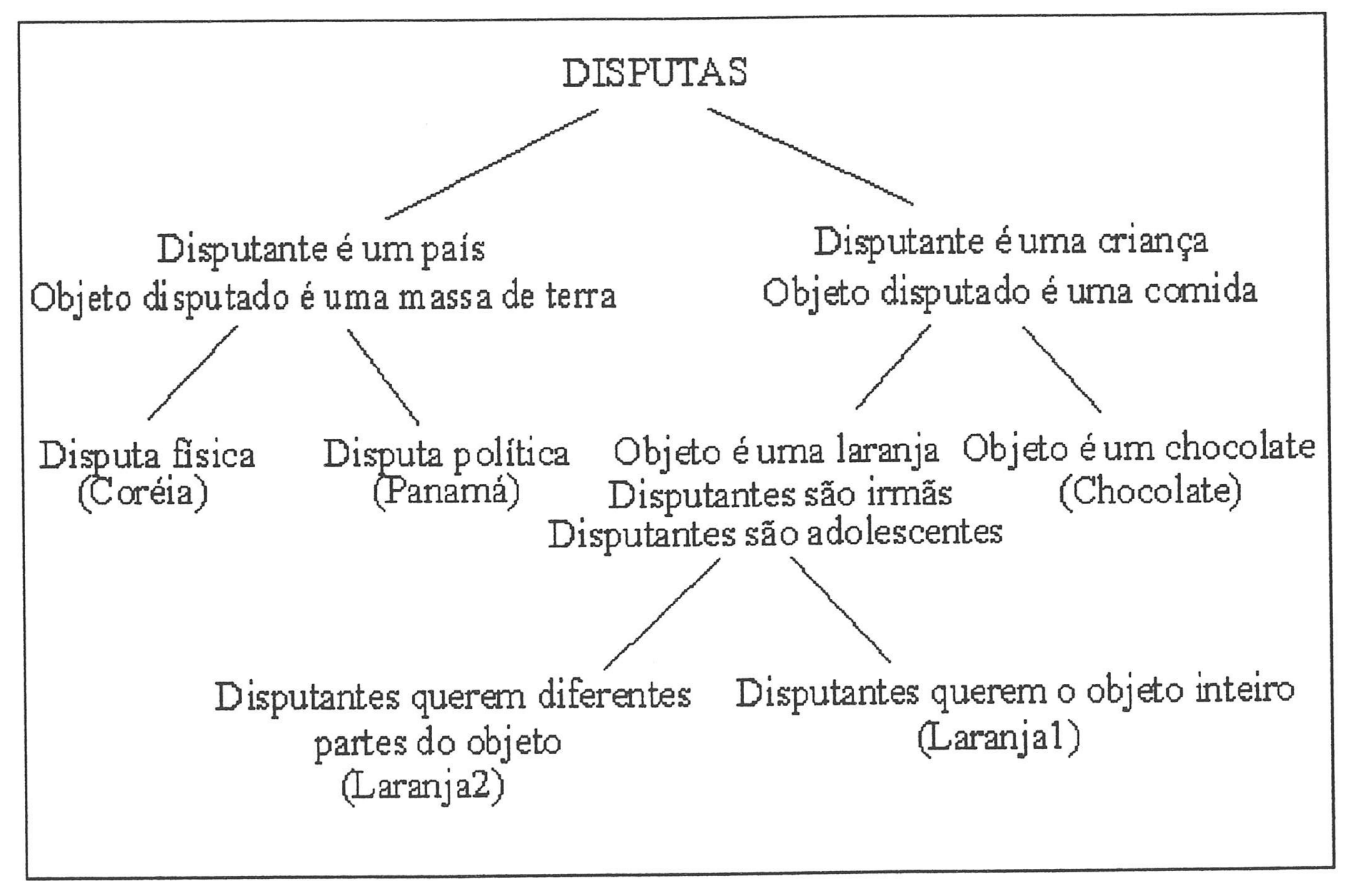

Figura 5.3: Rede de características compartilhadas (adaptada de [Kolodner 93]).

Ao incrementar ou atualizar a rede, ou seja, inserir um caso novo, é necessário encontrar um lugar na rede onde o novo caso se encaixe melhor e instalá-lo apropriadamente.

A vantagem da rede de características compartilhadas é a recuperação, que é mais eficiente do que quando se tem os casos organizados sequencialmente na Base 
de Casos. As desvantagens aparecem quando se adiciona um novo caso à Base de Casos. Esta operação é muito complexa, necessitando de espaço extra para reorganizar a Base de Casos. Outra desvantagem é que o melhor caso pode não ser recuperado se a rede não estiver em seu estado ótimo, ou seja, as características mais relevantes devem estar nos nós superiores.

\subsubsection{Redes de Discriminação por Prioridade - Busca em Profundidade}

Na organização dos casos descrita na Seção 5.2.2, como resultado do agrupamento de casos semelhantes ocorre indiretamente a priorização das características relevantes dos casos (discriminação dos casos). Uma alternativa organizacional é a rede de discriminação por prioridade [Feigenbaum 63], no qual o agrupamento dos casos é influenciado pelo resultado da priorização de suas características.

Cada nó interno da rede de discriminação é uma questão que subdivide o conjunto de casos armazenados em nós inferiores. Cada nó filho representa uma resposta diferente para a questão de seu nó pai. É importante comparar características mais relevantes antes, portanto estas devem vir nos nós de níveis superiores. A Figura 5.4 mostra um exemplo dos mesmos casos descritos anteriormente, retirados do sistema MEDIATOR [Kolodner 89], organizados em uma rede de discriminação por prioridade.

Utiliza-se para a estrutura de redes de discriminação por prioridade a busca em profundidade. A busca começa no topo da rede. Dependendo das características do caso novo em relação à primeira questão, um dos nós do nível inferior é selecionado. Este procedimento é repetido até um nó terminal ser encontrado.

Para construir uma rede de discriminação por prioridade, uma lista de prioridades das características dos casos deve ser feita. Os nós vão sendo criados a partir dos valores das características encontradas em cada caso. A primeira característica é colocada no topo da rede. A próxima característica a ser colocada na rede é a seguinte da lista de prioridades das características. Este processo se repete até que todos os casos sejam discriminados (colocados em diferentes nós da rede).

A utilização desta estrutura torna processo de recuperação mais eficiente do que quando os casos são organizados sequencialmente na Base de Casos. Outras vantagens são: facilidade em percorrer os nós da rede através de questões e respostas referentes às características do caso novo; fácil entendimento das conexões entre os casos da rede, já que as questões e suas respostas em cada nó são os índices 


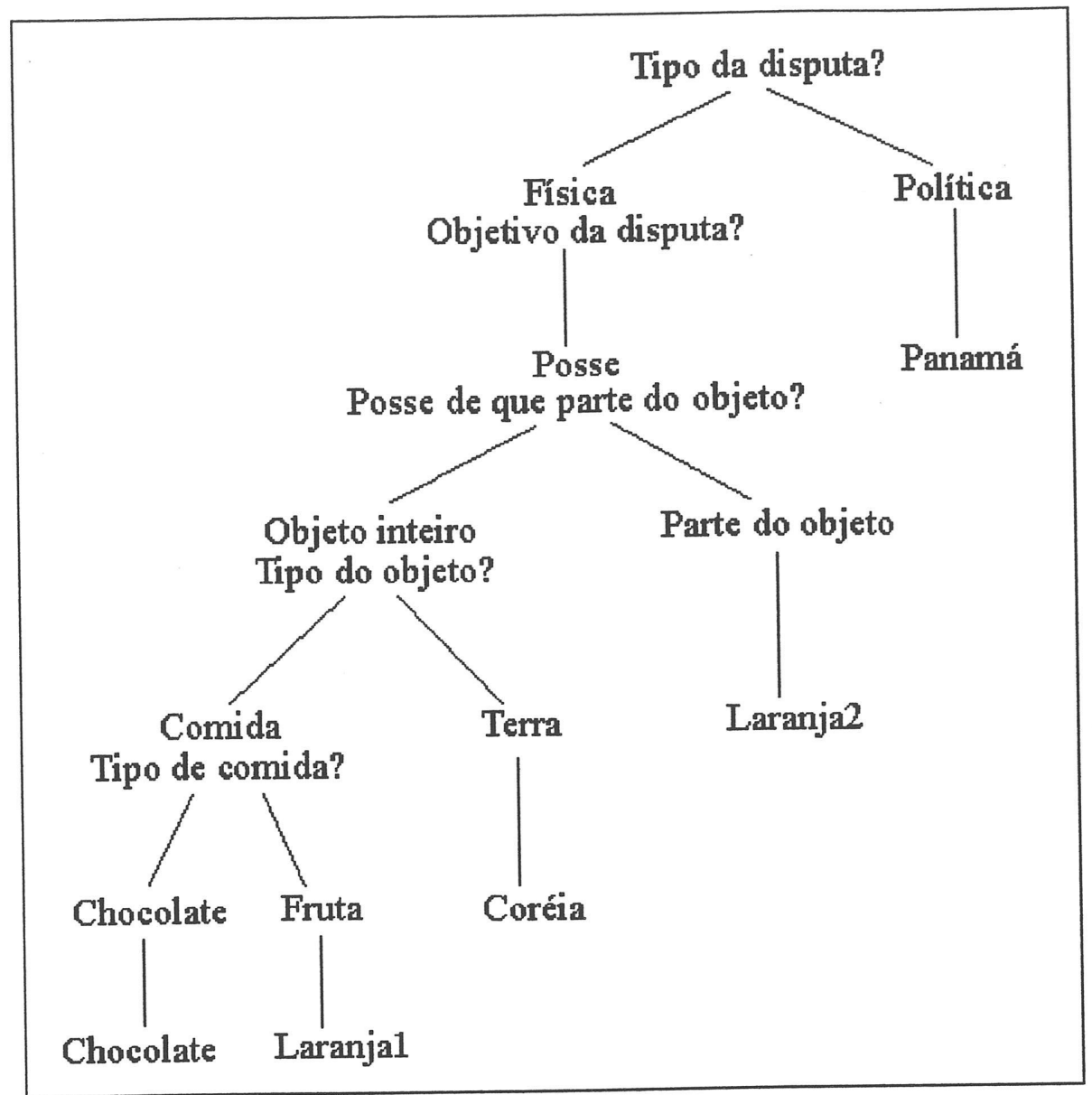

Figura 5.4: Rede de discriminação por prioridade (adaptada de [Kolodner 93]).

para os casos. A desvantagem é a mesma da encontrada na estrutura descrita na Seção 5.2.2, a complexidade em se adicionar um caso novo na Base de Casos. Uma outra desvantagem que é compartilhada pelas estruturas de redes de características compartilhadas e redes de discriminação por prioridade é que nenhuma destas redes fornecem uma orientação de como continuar a busca quando a descrição do caso novo está incompleta. Há algumas opções para lidar com este problema, mas todas apresentam problemas [Porter 90].

\subsubsection{Redes de Discriminação Redundante - Busca em Largura}

Redes de discriminação redundantes [Kolodner 83b, Kolodner 84] fornecem mecanismos para o problema de informações incompletas. Uma rede de discriminação 
reduntante organiza os casos utilizando diferentes redes de discriminação por prioridade, cada uma utilizando uma ordem de discriminação diferente. As redes são percorridas por um algoritmo de busca em largura. Se não há resposta para um questão em uma rede, a busca continua em outra rede.

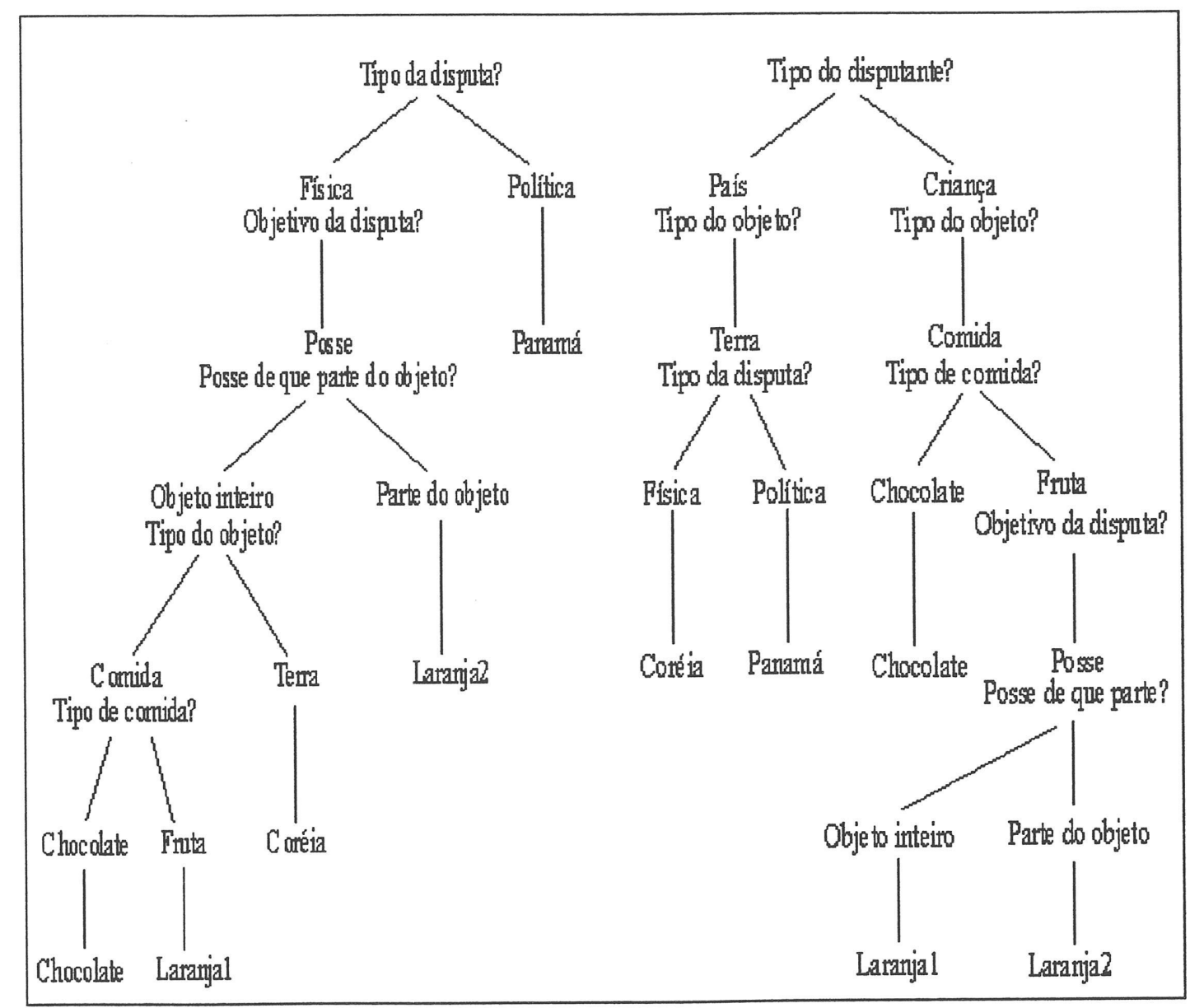

Figura 5.5: Redes de discriminação redundante.

As vantagens deste tipo de estrutura são: as já citadas nas Seções 5.2.2 e 5.2.3; e os vários caminhos diferentes pelo qual um caso pode ser recuperado quando as informações da descrição de um caso novo são incompletas.

As desvantagens desta estrutura são a complexidade em se atualizar a Base de Casos; grande espaço de memória requerido para armazenar as redes e o alto custo dos procedimentos para adicionar casos novos na Base de Casos. Um outro problema é a não priorização das redes de discriminação redundantes (carac- 
terísticas menos importantes virem antes das mais importantes nas redes), dado que muitos casos semelhantes, mas não potencialmente bons, podem ser recuperados. Algumas variações deste esquema [Koton 89, Hinrichs 92, Simpson 85] visam solucionar este problema.

\subsubsection{Memória Hierárquica - Busca Paralela}

Embora máquinas paralelas não imponham qualquer organização dos casos na Base de Casos, isto é muitas vezes vantajoso. Portanto, seria interesse juntar as vantagens da memória hierárquica às vantagens do algoritmo de busca paralela. Como máquinas paralelas são caras poderia-se utilizar máquinas seriais para implementar um paralelismo implícito.

Uma maneira de implementar memória hierárquica utilizando busca paralela é designando cada nó da hierarquia de casos para um processador, ver Figura 5.6. A recuperação é obtida espalhando cada par de características atributo-valor do caso novo para a memória, setando todo nó da estrutura hierárquica que possui aquele par. Os nós mais específicos nas subârvores abaixo de cada nó que foi ativado somam o número de nós antecedentes ativados. Aqueles nós cuja soma total superar um determinado valor são selecionados. Uma função de matching é então aplicada à cada um dos casos selecionados, levando em consideração a importância das características. Esta forma de implementar memória hierárquica com busca paralela pode ser encontrado em [Kolodner 88].

A vantagem de tal esquema é a combinação das vantagens dos esquemas que utilizam hierarquia de casos com as vantagens de esquemas que utilizam busca paralela. A recuperação é eficiente. A respeito das desvantagens, é difícil apontá-las, uma vez que não há muitas implementações deste esquema. Mas, uma desvantagem evidente é que a recuperação pode apresentar muitos casos, o que requer muito trabalho das funções de matching depois da execução dos algoritmos de recuperação.

\subsection{Conclusão}

Neste capítulo foram apresentados, de forma resumida, alguns algoritmos de recuperação de casos e os esquemas organizacionais da Base de Casos correspondentes à cada algoritmo, bem como as vantagens e desvantagens de cada uma das alternativas. 


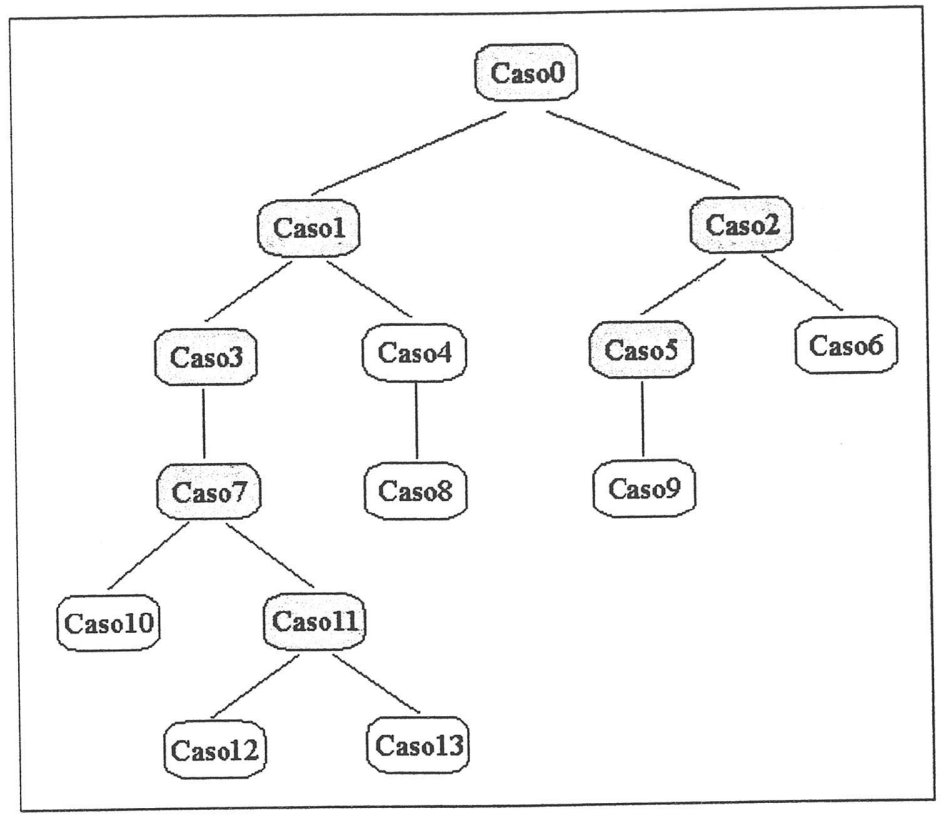

Figura 5.6: Casos são organizados em hierarquias.

Recuperar casos não pode ser tratado e resolvido como um problema isolado, pois está fortemente relacionado à etapa de aprendizado, como foi exposto no decorrer deste capítulo. Aprender em Raciocínio Baseado em Casos significa extrair conhecimento relevante de experiências, integrar um caso dentro de uma estrutura de conhecimento existente, e indexar o caso para mais tarde "casá-lo" com casos semelhantes. Tanto aprender como recuperar casos dependem da organização dos casos na memória, das estruturas para armazená-los e dos índices que auxiliam na busca do melhor caso. A diferença está na simplicidade ou complexidade com que são resolvidos estes problemas. Geralmente, quanto mais eficiente é a etapa de recuperação, mais complexa será a organização, armazenagem e indexação dos casos. Quanto mais fácil e consequentemente mais barata é a etapa de aprendizado, mais simples será a organização, armazenagem e indexação dos casos na Base de Casos, porém mais lenta será a recuperação destes casos. 


\section{Capítulo 6}

\section{Um Sistema Híbrido de RBC para o Domínio da Culinária}

\subsection{Introdução}

Como resultado da investigação sobre a integração de Raciocínio Baseado em Casos e Redes Neurais, foi implementado um protótipo de um sistema híbrido de Raciocínio Baseado em Casos. Este protótipo foi desenvolvido utilizando a linguagem de programação lógica PROLOG e seu comportamento será investigado neste capítulo.

Conforme descrito no Capítulo 1, este trabalho propõe um modelo de recuperação e aprendizado de casos de um sistema de Raciocínio Baseado em Casos que seja ao mesmo tempo eficiente e simples. Portanto, a ênfase maior é sobre os processos de recuperação de casos e aprendizado de casos. No protótipo implementado, os processos de reuso de casos e revisão/reparo de casos são feitos pelo usuário do sistema, manualmente.

Neste trabalho, uma Rede Neural foi utilizada para recuperação e aprendizado de casos. A Rede Neural foi implementada como parte (compondo um módulo) do protótipo do sistema de Raciocínio Baseado em Casos. Inicialmente, foi implementado o modelo ART2, que aceita vetores de valores reais como padrão de entrada para a rede. O modelo ART2 foi escolhido devido ao domínio que se pretendia utilizar para testar o sistema. O domínio em questão referia-se ao controle da qualidade da água. No decorrer do trabalho, devido a questões que serão mencionadas na Seção 6.2, optou-se pelo domínio da culinária. Como os 
dados deste domínio puderam ser codificados em vetores binários, o modelo da Rede Neural foi também mudado para ART1. O modelo ART1 aceita vetores de valores binários como padrão de entrada para a rede, atendendo assim às nossas necessidades, além de ser mais simples que o modelo ART2.

Este capítulo descreve o domínio utilizado para testar preliminarmente o protótipo, sua arquitetura e ainda alguns testes realizados e os resultados obtidos.

\subsection{Domínio}

Inicialmente, a proposta deste trabalho era a integração de Raciocínio Baseado em Casos e Redes Neurais aplicado ao controle da qualidade de água. Os dados seriam fornecidos pelo SAAE (Estação de Tratamento de Água de São Carlos). Várias entrevistas informais foram realizadas para aquisição dos dados. Por algumas razões, entre elas a dificuldade de comunicação das diferentes áreas envolvidas; e o modo como o controle da qualidade de água é feito pelo SAAE (envolvendo muita experiência e feeling das pessoas envolvidas no controle da qualidade de água), não foi possível a obtenção dos dados na forma de casos. Optou-se então pelo domínio da culinária. A culinária é um domínio interessante e de difícil modelagem devido aos conhecimentos abrangentes de que trata. Alguns trabalhos [Hammond 89, Kolodner 87, Lopes 95] abordaram este domínio e serão descritos brevemente a seguir.

Em [Lopes 95] é proposto um modelo de Raciocínio Baseado em Casos que divide o conhecimento em várias partições. Cada partição refere-se a informações referentes a ingredientes, modo de preparo, operações utilizadas no modo de preparo e resultados. As informações referentes à cada partição são organizadas independentemente. Os casos são representados através de escaninhos (slots). Cada escaninho armazena informações correspondentes à cada uma das partições. O conhecimento específico contido em cada partição está representado e organizado. A especificação do caso de entrada deve conter informações referentes às informações contidas nas partições. Para recuperar os casos é utilizada uma forma híbrida de indexação: hierárquica e associativa. A indexação hierárquica endereça os clusters dos casos que compõem o conhecimento e a associativa utiliza a similaridade dos componentes do caso de entrada e dos casos presentes nos clusters indexados hierarquicamente. A adaptação se dá por eliminação de componentes, acréscimo de componentes, e substituição de componentes. O processo de aprendizado é feito pelo engenheiro do conhecimento que decide quais casos são importantes incorporar à Base de Casos. 
CHEF [Hammond 89] é um sistema de planejamento na área da culinária. Os casos de entrada deste sistema são descritos como submetas que devem ser satisfeitas (por exemplo: incluir carne de boi no prato, incluir brocolis no prato, utilizar fritura). A saída é um plano, ou seja, uma receita que é uma sequência de passos que devem ser seguidos para o preparo de um prato. Na representação do conhecimento são utilizados frames. Um frame faz referência a outro através de redes semânticas. CHEF indexa seus planos pelas submetas que eles seguem. Recuperar o melhor caso requer um maching direto de símbolos e um matching parcial baseado no significado dos símbolos. O processo de adaptação é realizado instanciando um plano velho com novos objetos (por exemplo, na criação de um prato com frango e brócolis utilizando uma receita que contém carne de boi e ervilhas, a carne de boi é substituída por frango e as ervilhas por brócolis). Para criar uma nova receita, as vezes é necessário modificar, por exemplo, a ordem de operações tais como limpar ou desossar o frango antes de fritá-lo. Quando um plano não é bem sucedido, o sistema tenta aprender com esta situação. São criadas explanações sobre a causa da falha. O caso é então indexado pela falha e armazenado com o objetivo de previnir falhas futuras.

JULIA [Hinrichs 88, Kolodner 87] é um sistema que utiliza Raciocínio Baseado em Casos com o objetivo de propor pratos. Os problemas a serem solucionados são descritos em termos de restrições (por exemplo: há convidados vegetarianos, a refeição deve ter um custo barato) que devem ser cumpridas. A solução descreve um prato que satisfaça as restrições. Geralmente, os problemas são grandes, o que torna necessário decompô-los e solucioná-los separadamente. Entretanto, as partes decompostas se relacionam fortemente. O conhecimento embutido no sistema é específico e geral. O conhecimento específico pode ser formado por requisitos específicos impostos pelo usuário. Por exemplo, que o prato tenha determinado ingrediente como ingrediente principal. O conhecimento geral é formado por requisitos válidos para todos os pratos de uma determinada classe. Por exemplo, informações sobre pratos servidos em buffet. Para resolver um problema, JULIA seleciona o protótipo do prato mais geral e propaga as restrições do problema. As restrições são utilizadas como índices. O usuário é questionado em busca de mais informações e para checar algumas inferências feitas pelo sistema. Na adaptação são utilizadas algumas regras de transformação, como por exemplo, deletar ingredientes, acrescentar ingredientes e substituir um ingrediente por outro. 


\subsection{Arquitetura do Protótipo}

O protótipo do sistema que integra $\mathrm{RBC}$ e $\mathrm{RN}$ foi implementado na linguagem de programação lógica PROLOG. Esta linguagem foi escolhida por permitir fácil e rápida implementação de protótipos. Este protótipo consiste da Rede Neural do tipo ART1, de uma Base de Casos e de módulos de Recuperação, Reuso, Revisão/Reparo e Armazenamento. A Figura 6.1 mostra a arquitetura geral deste protótipo.

A Rede Neural é utilizada para auxiliar na recuperação e aprendizado de casos. Durante a fase de treinamento, a rede extrai automaticamente as características mais relevantes dos padrões de treinamento, armazenando-as na forma de pesos. Os padrões de treinamento são os casos, que são codificados para que a rede possa utilizá-los.

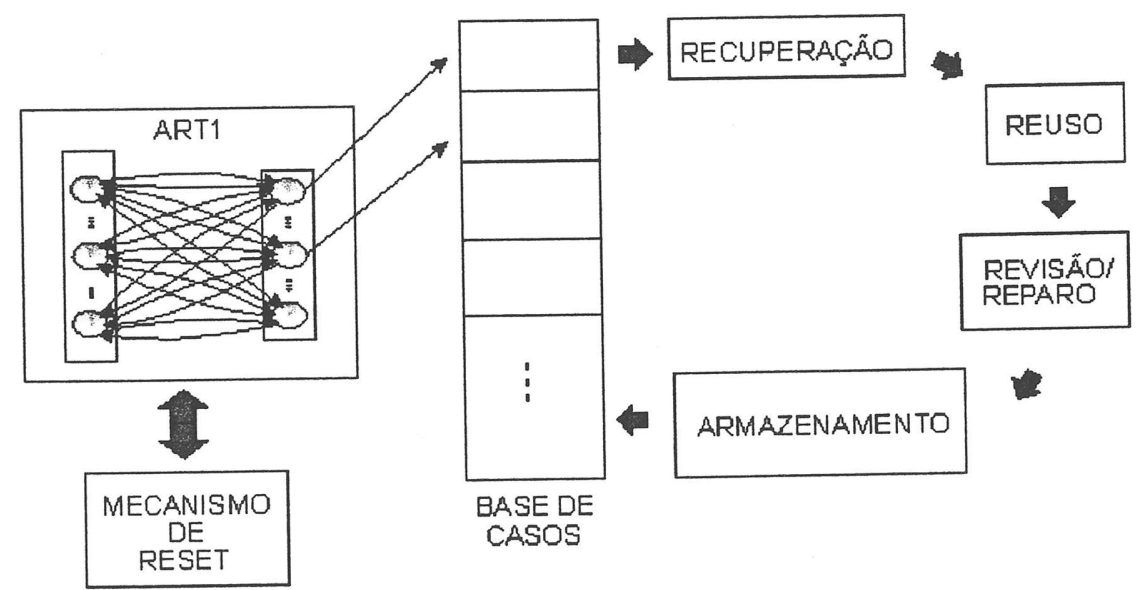

Figura 6.1: Arquitetura geral do protótipo de um sistema de RBC.

Ao longo do treinamento os padrões são agrupados em clusters, de acordo com a similaridade entre eles. O número de clusters criados para acomodar os padrões é determinado pela rede. Isto se deve ao tipo de aprendizado utilizado por ART1, aprendizado não supervisionado. Os clusters são representados pelos neurônios da camada de saída da rede e servem como índices dos casos.

É importante esclarecer que a rede não recuperará o melhor caso (o caso mais semelhante) para um caso apresentado como entrada do sistema. A rede auxiliará 
na recuperação, associando o novo caso a um cluster cujo protótipo seja semelhante, se este cluster existir. Dentro deste cluster deverá haver um ou mais casos parecidos com o caso novo. O melhor caso será selecionado a partir destes casos através de uma função de matching. Portanto, a rede ART1 realiza um matching parcial.

Terminada a fase de treinamento, o sistema armazena os casos iniciais que compõem a Base de Casos. Estes casos ficam armazenados na Base de Casos sequencialmente, indexados pelo cluster associado pela rede. As características mais relevantes de cada um destes casos estão também armazenadas na rede ART1 implicitamente através dos pesos, facilitando assim o processo de definição de similaridade entre um novo caso e os clusters. A seguir é mostrado um exemplo de como o sistema funciona depois que a rede já foi treinada.

Entre com um novo caso.

Digite os ingredientes principais deste caso: 1: [oleo,maca, acucar, farinha].

Digite o grau de semelhanca requerido: $1: 0.8$.

O sistema recuperou os casos: 1: [bolo_de_cenoura, bolo_de_beterraba, bolo_de_chocolate].

A tabela abaixo mostra as receitas recuperadas.

$\begin{array}{lccc}\text { Receitas } & \text { Ingredientes } & \text { Calorias } & \text { Tempo de Preparo } \\ \text { bolo_de_cenoura } & 3 & 6235 & 60 \mathrm{~min} \\ \text { bolo_de_beterraba } & 3 & 6183 & 60 \mathrm{~min} \\ \text { bolo_de_chocolate } & 3 & 4636 & 40 \mathrm{~min}\end{array}$

Selecione uma receita digitando seu nome: 1: bolo_de_chocolate.

Modo de preparo: Bater no liquidificador ate fazer bolhas:

3 ovos, 1 xicara de oleo, $1 / 2$ de acucar, 1 de chocolate, 1 de agua fervendo e 1 colher de fermento. Acrescentar 2 xicaras de farinha e misturar. Assar em fogo baixo por 40 minutos. 
Deseja aprender este novo caso? I: nao.

Deseja apresentar um novo caso? I: sim.

Entre com um novo caso.

Digite os ingredientes principais deste caso: 1: [leite, batata].

Digite o grau de semelhanca requerido: $1: 0.8$.

Nao consigo recuperar nenhum caso!

Voce deseja:

1. Criar novo cluster?

2.Modificar a semelhanca entre os casos?

Digite sua opcao: 1: 1 .

Nome da receita: 1: pure_de_batata.

Ingredientes: 1: [oleo, batata,leite].

Modo de preparo: 1: Frite uma cebola no oleo ou manteiga.

Acrescente: $1 / 2 \mathrm{~kg}$ de batata cozida e amassada, 1 copo de leite e sal a gosto. Deixe cozinhar por 10 minutos, mexendo.

Tempo de preparo (em minutos): 10 .

Calorias: 1398.

Deseja apresentar um novo caso? I: nao.

yes

1?-

Quando um caso novo é apresentado ao sistema, este tenta associá-lo a um dos clusters existentes, utilizando as características relevantes armazenadas para os 
casos anteriores. Os pesos da rede, portanto, funcionam como índices dos clusters, facilitando a fase de indexação. Se um caso novo não se assemelha a nenhum dos clusters, o sistema consulta o usuário sobre a conveniência de armazená-lo ou tentar novamente recuperar casos semelhantes diminundo a semelhança requerida entre os casos. Se o usuário decidir procurar por casos menos semelhantes, deverá informar o novo valor de $\rho$. Por outro lado, se o usuário decidir criar um novo cluster, a rede seleciona um neurônio livre da camada de saída para representar este novo cluster. Estes neurônios livres da camada de saída são neurônios que não foram utilizados previamente para representar clusters de casos. Eles ficam disponíveis para situações em que um novo caso apresentado ao sistema é muito diferente dos casos já armazenados, não se encaixando em nenhum cluster e há o interesse do usuário em incorporá-lo à Base de Casos.

Quando um novo cluster é criado para acomodar um caso novo, um neurônio livre da camada de saída é designado para representá-lo e os pesos da rede associados a este neurônio são atualizados para incorporar as características deste caso sem perder quaisquer características dos casos previamente armazenados. Assim, o sistema aprende, ou seja, atualiza e aumenta seu conhecimento sem se desfazer de nenhuma informação anteriormente adquirida.

A unidade de reset da rede ART1 é responsável por testar a similaridade entre o caso novo e os armazenados previamente. Para isto há o threshold de vigilância $(\rho)$ que determina se um novo cluster de casos pode ser criado para um caso novo apresentado à rede. Quanto maior o valor de $\rho$, maior terá que ser a semelhança entre um cluster e um caso novo para que este seja classificado neste cluster. No protótipo implementado, o valor de $\rho$, é controlado pelo usuário. Se o usuário desejar encontrar um caso prévio bastante semelhante ao caso novo, o valor de $\rho$ deverá ser setado com um valor alto entre 0.8 e 1.0 por exemplo.

Maiores detalhes a respeito da implementação do protótipo poderão ser encontradas no relatório técnico [Milaré 97b] submetido para publicação pela Biblioteca do Instituto de Ciências Matemáticas de São Carlos, Universidade de São Paulo.

\subsection{Experimento}

Como descrito acima, devido a dificuldade de obtenção dos dados para o tratamento de água, optou-se por trabalhar com dados do domínio da culinária. Inicialmente, os casos apresentados ao sistema eram ingredientes de receitas culinárias codificadas em um vetor binário. Este vetor era composto de 30 posições, no qual as 24 primeiras posições representavam a ausência ( 0 binário) ou presença 
(1 binário) de um determinado ingrediente. As posições 25, 26 e 27 representavam os valores fuzzy das calorias totais de uma determinada receita. As demais posições, 28, 29 e 30, codificavam valores fuzzy referentes ao tempo de preparo da receita. A estrutura de armazenamento dos casos pode ser vista na Figura 6.2.

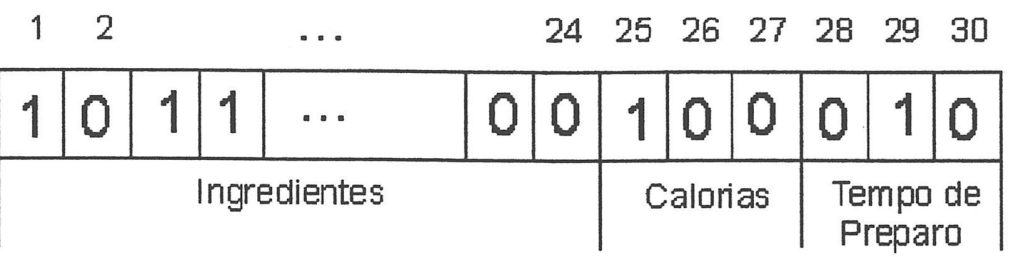

Figura 6.2: Estrutura de armazenamento dos casos.

A rede foi treinada com 20 casos para compôr inicialmente a Base de Casos. O resultado do agrupamento dos casos em clusters não foi o esperado. Havia situações em que dois casos bastante semelhantes eram alocados em clusters diferentes, por exemplo, os casos mousse_de_maracuja e mousse_de_chocolate. Isto se deve ao fato de que os casos envolvidos tinham diferenças razoáveis no que se refere aos totais calóricos e ao tempo de preparo. Decidiu-se então utilizar somente os ingredientes de cada caso como informação para treinar a Rede Neural. As outras informações, totais calóricos e tempo de preparo, passariam a ser utilizadas na etapa posterior da recuperação dos casos prévios.

Os vetores que representavam os casos para treinamento da rede passaram a ser compostos por 24 posições, representando 24 ingredientes com posições prédeterminadas. Treinou-se a rede com 27 casos iniciais variando os valores dos parâmetros $\rho$ e $L$. Sendo $\rho$ o parâmetro (threshold de vigilância) que determina a formação de um novo cluster e $L$, um parâmetro utilizado na atualização dos pesos da rede. Os resultados podem ser visualizados na Tabela 6.1.

A primeira coluna da Tabela 6.1 corresponde aos valores de $L$ e $\rho$. A segunda coluna refere-se ao número de clusters criados para acomodar os padrões. A terceira coluna diz respeito à porcentagem de acerto na classificação dos padrões em seus clusters. Para determinar a porcentagem de acerto da rede, os 27 padrões de treinamento foram classificados em 13 clusters. Esta classificação considerou não só informações referentes aos ingredientes, mas também informações heurísticas, difíceis de serem traduzidas e codificadas, como por exemplo, o sabor.

Pela Tabela 6.1 nota-se que na melhor classificação, 70,37\%, o valor de $\rho$ está entre 0.4 e $0.5 \mathrm{com}$ valor de $L$ entre 1 e 4 . Foi observado que a rede não tem um bom comportamento para padrões que possuem poucos valores iguais a 1 no seu vetor de ingredientes. Isto ocorre porque a rede ART1 não trata os valores 1 e 0 


\begin{tabular}{||c|c|c||}
\hline \hline Parâmetros & Número de Cluster & Classificação Correta \\
\hline$L=1, \rho=0.5$ & 14 & $\mathbf{7 0 , 3 7 \%}$ \\
\hline$L=2, \rho=0.5$ & 14 & $\mathbf{7 0 , 3 7 \%}$ \\
\hline$L=2, \rho=0.55$ & 18 & $66,66 \%$ \\
\hline$L=3, \rho=0.4$ & 12 & $\mathbf{7 0 , 3 7 \%}$ \\
\hline$L=3, \rho=0.45$ & 14 & $\mathbf{7 0 , 3 7 \%}$ \\
\hline$L=3, \rho=0.49$ & 14 & $\mathbf{7 0 , 3 7 \%}$ \\
\hline$L=3, \rho=0.5$ & 14 & $\mathbf{7 0 , 3 7 \%}$ \\
\hline$L=3, \rho=0.55$ & 18 & $66,66 \%$ \\
\hline$L=4, \rho=0.5$ & 14 & $\mathbf{7 0 , 3 7 \%}$ \\
\hline
\end{tabular}

Tabela 6.1: Resultados do teste variando $\rho$ e $L$.

simetricamente [Gallant 93]. O valor 1 tem um papel muito mais importante na definição de similaridades e atualização dos pesos que o valor 0 . Por exemplo, se um padrão $X$ é associado a um protótipo $P_{i}$ que apresenta muitos $1^{\prime} s$, então $X$ é considerado um membro do cluster $P_{i}$ e as diferenças são atribuídas às características sem importância ou à ruídos. Por outro lado, se $P_{i}$ tem poucos $1^{\prime} s$, a mesma diferença entre $P_{i}$ e $X$ torna-se significativa.

Para solucionar o problema da assimetria entre $1^{\prime} s$ e $0^{\prime} s$, foi utilizada uma solução proposta em [Gallant 93]. Esta solução consiste em duplicar o tamanho dos padrões e colocar o valor 1 na segunda cópia onde havia um valor 0 na primeira cópia e vice-versa. Isto faz com que todos os padrões tenham o mesmo número de $1^{\prime} s$ e $0^{\prime} s$. Para ilustrar, suponha um padrão com 5 posições como o da Figura 6.3 .

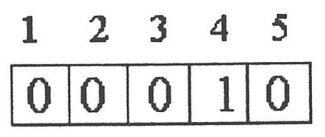

Figura 6.3: Padrão com 5 posições.

Solucionando o problema da assimetria para este padrão, tem-se como padrão resultante um padrão de 10 posicões como o da Figura 6.4. Na posição 2 do vetor tem-se o valor 0 , na segunda cópia na posição correspondente, posição 7 , é colocado o valor 1 .

Depois de resolvido o problema da assimetria, a rede foi novamente treinada com os 27 padrões duplicados, ou seja, padrões de 48 posições. Novamente diferentes valores de $\rho$ e de $L$ foram utilizados ao longo dos testes. A Tabela 6.2 mostra os 


\section{$\begin{array}{llllllllll}1 & 2 & 3 & 4 & 5 & 6 & 7 & 8 & 9 & 10\end{array}$

\begin{tabular}{|l|l|l|l|l|l|l|l|l|l|}
\hline 0 & 0 & 0 & 1 & 0 & 1 & 1 & 1 & 0 & 1 \\
\hline
\end{tabular}

Figura 6.4: Padrão duplicado.

resultados obtidos.

\begin{tabular}{||c|c|c||}
\hline \hline Parâmetros & Número de Cluster & Classificação Correta \\
\hline$L=1, \rho=0.84$ & 18 & $29,62 \%$ \\
\hline$L=2, \rho=0.8$ & 11 & $81,48 \%$ \\
\hline$L=2, \rho=0.83$ & 11 & $81,48 \%$ \\
\hline$L=2, \rho=0.835$ & 12 & $81,48 \%$ \\
\hline$L=2, \rho=0.84$ & 12 & $\mathbf{8 5 , 1 8 \%}$ \\
\hline$L=2, \rho=0.85$ & 12 & $77,7 \%$ \\
\hline$L=2, \rho=0.87$ & 16 & $74,07 \%$ \\
\hline$L=2, \rho=0.9$ & 17 & $74,07 \%$ \\
\hline$L=3, \rho=0.835$ & 12 & $81,48 \%$ \\
\hline$L=3, \rho=0.84$ & 12 & $\mathbf{8 5 , 1 8 \%}$ \\
\hline$L=4, \rho=0.84$ & 12 & $\mathbf{8 5 , 1 8 \%}$ \\
\hline
\end{tabular}

Tabela 6.2: Resultados do teste variando $\rho$ e $L$.

Percebe-se pela Tabela 6.2 que os valores de $\rho$ são maiores que os da Tabela 6.1. Isto porque cada padrão agora tem $241^{\prime} s$. Nota-se também que a porcentagem de classificação correta aumentou consideravelmente, sendo que o melhor resultado foi gerado com valor de $\rho$ igual a 0.84 e com valor de $L$ igual ou maior a 2 .

Posteriormente, foram apresentados à rede mais 12 casos. Dentre estes casos haviam casos bastante diferentes, outros no qual algumas informações não estavam disponíveis e alguns casos semelhantes, mas não idênticos aos de treinamento. $\mathrm{O}$ sistema associou $83,33 \%$ destes casos corretamente.

Quando um novo caso é apresentado ao sistema, o valor de $\rho$ também deve ser informado. Com isto o usuário pode decidir quão semelhante ao novo caso ele deseja que o caso prévio recuperado seja. Quando o novo caso é muito diferente dos casos armazenados, o usuário é consultado para diminuir o valor de $\rho$ ou para criar um novo cluster. Determinado o cluster no qual o caso novo pertence, é mostrado ao usuário todos os casos contidos naquele cluster, ou seja, os nomes das receitas, seus ingredientes, suas calorias e o tempo de preparo. O usuário seleciona aquela que melhor lhe convém (a que combina o maior número de ingredientes 
com o caso novo, ou a receita com menos calorias ou ainda a receita com menor tempo de preparo) e então é mostrado o modo de preparo da receita selecionada. Se o usuário desejar aprender o caso novo, o sistema lhe pergunta o nome da receita, o modo de preparo, as calorias, o tempo e os ingredientes.

Assim, na segunda etapa do processo de recuperação, ou seja, encontrar qual o melhor dos casos prévios contidos dentro do cluster que a Rede Neural associou ao caso novo, o usuário é quem realiza o procedimento de matching, tendo disponíveis informações à respeito dos ingredientes, calorias totais e tempo de preparo. Este procedimento poderia também ser facilmente realizado pelo sistema de várias formas. Uma delas é calcular a distância Euclidiada entre os casos do cluster selecionado e o novo caso.

O processo de reuso de um caso prévio é feito pelo usuário manualmente. Quando ele seleciona o melhor caso prévio, o sistema lhe mostra o modo de preparo do caso selecionado. O usuário então tem uma sugestão de como preparar a sua receita e pode modificá-la para atender às suas necessidades.

\subsection{Avaliando o Modelo Proposto}

Com o intuito verificar os resultados obtidos na formação de clusters e recuperação de casos pela rede ART1, o mesmo conjunto de treinamento e teste foi aplicado a um algoritmo de clustering bastante conhecido, o algoritmo $K$ Nearest Neighbor (K-Vizinhos mais Próximos) [Fairhurst 88]. Este algoritmo foi implementado em um programa de domínio público encontrado no endereço http://www.mcs.com/ ${ }^{\sim}$ drt/home.html. A seguir o algoritmo K-Nearest Neighbor será descrito brevemente, bem como os resultados dos testes realizados.

\subsubsection{K-Nearest Neighbor}

A idéia do algoritmo K-Nearest Neighbor é utilizar um conjunto de padrões conhecidos para classificar um padrão não conhecido. Isto é realizado através de uma regra que seleciona um conjunto dos $K$ padrões de um ou mais clusters que são mais semelhantes ao padrão não conhecido desconhecido. $\mathrm{O}$ cluster que tiver mais representantes dentro do conjunto dos $K$ padrões, será selecionado para acomodar o padrão não conhecido. A regra que determina os $K$ padrões mais semelhantes para o algoritmo K-Nearest Neighbor utilizado neste trabalho é a distância Euclidiana, que também é utilizada na formação dos clusters a partir 
do conjunto de treinamento.

O algoritmo K-Nearest Neighbor foi aplicado ao conjunto de treinamento, variando os valores para $K$. O melhor resultado obtido foi com o valor de $K$ igual a 1 como mostra a Tabela 6.3. Isto sugere que os padrões (casos) de cada cluster estão bem espalhados. Devido a estes resultados, nos testes descritos a seguir utilizando o algoritmo K-Nearest Neighbor, usou-se valor igual a 1 para $K$.

\begin{tabular}{||c|c|c||}
\hline \hline$K$ & Número de Clusters & Classificação Correta \\
\hline 1 & 9 & $\mathbf{6 6 , 6 6 \%}$ \\
\hline 2 & 8 & $59,25 \%$ \\
\hline 3 & 7 & $51,85 \%$ \\
\hline 4 & 7 & $48,14 \%$ \\
\hline 5 & 7 & $37,03 \%$ \\
\hline
\end{tabular}

Tabela 6.3: Variando $K$ no algoritmo K-Nearest Neighbor.

Os resultados comparando o número de clusters e a classificação correta dos padrões do conjunto de treinamento utilizando a rede ART1 tanto com os padrões duplicados (solucionada a assimetria entre 1 e 0 ) quanto com os padrões originais e o algoritmo K-Nearest Neighbor são mostrados na Tabela 6.4 .

\begin{tabular}{||c|c|c||}
\hline \hline & Número de Cluster & Classificação Correta \\
\hline ART1 (duplicado) & 12 & $\mathbf{8 5 , 1 8 \%}$ \\
\hline ART1 (sem duplicar) & 14 & $70,37 \%$ \\
\hline ART1 (sem duplicar) & 12 & $70,37 \%$ \\
\hline K-Nearest Neighbor & 9 & $66,66 \%$ \\
\hline
\end{tabular}

Tabela 6.4: Resultados obtidos a partir do conjunto de treinamento.

Pela Tabela 6.4 nota-se que a rede ART1 com os padrões duplicados obteve um resultado melhor que o obtido pelo algoritmo K-Nearest Neighbor. Uma vantagem da rede ART1 sobre o algoritmo K-Nearest Neighbor é o número reduzido de clusters que serão pesquisados na recuperação de um padrão. Para associar um novo padrão ao cluster mais semelhante, a rede ART1 deverá comparar este novo padrão com 12 protótipos (um de cada cluster formado pela rede), já o algoritmo K-Nearest Neighbor deverá comparar o novo padrão com 27 padrões que corresponde ao número de padrões do conjunto de treinamento. Se conjunto de treinamento for grande um tempo razoável será gasto para isto.

O mesmo conjunto de teste aplicado à rede ART1 também foi aplicado ao algoritmo K-Nearest Neighbor. A rede ART1 obteve melhor desempenho na recupe- 
ração de padrões semelhantes do que o algoritmo K-Nearest Neighbor. A Tabela 6.5 mostra os resultados.

\begin{tabular}{||c|c||}
\hline \hline & Classificação Correta \\
\hline ART1 (duplicado) & $\mathbf{8 3 , 3 3 \%}$ \\
\hline K-Nearest Neighbor & $75,00 \%$ \\
\hline
\end{tabular}

Tabela 6.5: Resultados obtidos a partir do conjunto de teste.

\subsection{Conclusão}

Para integrar Raciocínio Baseado em Casos e Redes Neurais foi implementado um protótipo na linguagem de programação lógica PROLOG. Basicamente, este protótipo é um sistema de Raciocínio Baseado em Casos que utiliza a Rede Neural ART1 para auxiliar nos processos de recuperação e aprendizado de casos.

Alguns testes foram realizados com dados do domínio culinário. Nestes testes os parâmetros mais críticos da rede ART1 foram variados e conseguiu-se o melhor resultado com valor de $\rho$ igual a 0.84 e valor de $L$ igual ou maior a 2. Para o melhor resultado, a rede formou 12 clusters e classificou $85,18 \%$ dos padrões de treinamento corretamente.

A fim de verificar o comportamento da rede ART1, utilizou-se o mesmo conjunto de padrões de treinamento e teste, aplicados à rede ART1, com o algoritmo $K$ Nearest Neighbor. Apesar dos resultados dos testes serem favoráveis à utilização da rede ART1, não se pode concluir categoricamente que a rede ART1 é melhor que o algoritmo $K$-Nearest Neighbor. Isto em razão ao tamanho e natureza dos conjuntos de treinamento e teste. 


\section{Capítulo 7}

\section{Conclusão}

\subsection{Sobre o Trabalho}

Este trabalho preocupou-se com a integração de dois paradigmas de Inteligência Artificial, Raciocínio Baseado em Casos e Redes Neurais. Atualmente, tanto as pesquisas envolvendo Raciocínio Baseado em Casos como aquelas relacionadas a Redes Neurais buscam integrar cada uma destas abordagens com outras técnicas para melhorar o desempenho obtido na resolução de problemas nas mais variadas áreas. Ao realizar a integração de vários paradigmas espera-se compensar as deficiências referentes à cada um dos paradigmas envolvidos, tornando a resolução de problemas mais eficiente do que se conseguiria normalmente, utilizando apenas uma abordagem.

Dentre as inúmeras características de Redes Neurais, vistas no Capítulo 2, sua capacidade de generalização e aprendizado são muito importantes neste trabalho. Estas características estão intimamente relacionadas com as tarefas de recuperação e aprendizado de casos, de responsabilidade das Redes Neurais no sistema de Raciocínio Baseado em Casos neste trabalho.

Raciocínio Baseado em Casos por sua vez é um paradigma bastante útil na resolução de problemas cujo domínio ainda não foi vastamente estudado, ou seja, domínios que não têm ainda um modelo formal definido, chamados de domínios abertos. É possível resolver problemas de domínios abertos utilizando Raciocínio Baseado em Casos devido à maneira como este paradigma trata estes problemas, como casos; e resolve-os, por analogia. Um caso para um sistema de Raciocínio Baseado em Casos é uma experiência prévia, ou seja, um problema que já foi solucionado anteriormente e agora é utilizado para solucionar problemas seme- 
lhantes que possam surgir. Resolução por analogia é lembrar de um problema semelhante que já tenha sido resolvido anteriormente e utilizá-lo na resolução de um novo problema.

A idéia básica na resolução de um problema utilizando Raciocínio Baseado em Casos é muito simples. Os seres humanos utilizam um método semelhante a Raciocínio Baseado em Casos a todo instante para solucionar seus problemas cotidianos. Dada a descrição de um novo caso como entrada para um sistema de $\mathrm{RBC}$, este deve buscar, em sua memória de casos, um caso armazenado que se pareça com o novo caso. A seguir, o sistema deve modificar as partes do caso recuperado que não se ajustam à descrição de entrada. Como resultado desta modificação tem-se uma solução para o problema proposto e um novo caso que poderá ser adicionado à memória de casos do sistema. Ao implementar esta idéia na prática surge uma série de problemas que geralmente não são fáceis de resolver. Dois destes problemas, recuperação de casos e aprendizado de casos, têm sido alvo de pesquisas recentes.

Neste trabalho, é proposto um modelo híbrido que tenta amenizar as dificuldades inerentes à realização das tarefas de recuperação de casos e aprendizado de casos em um sistema de Raciocínio Baseado em Casos, bem como tornar estas tarefas eficientes e simples. Para isto utilizou-se uma Rede Neural, modelo ART1, para auxiliar na execução destas etapas. O modelo ART1 foi escolhido por se tratar de um modelo de Rede Neural que suporta aprendizado incremental. Aprendizado incremental é uma característica indispensável para sistemas que devem ao longo do tempo atualizar seu conhecimento prévio incorporando conhecimentos novos. Sistemas de Raciocínio Baseado em Casos devem possuir esta característica.

Para testar na prática o modelo proposto, foi implementado um protótipo de um sistema de Raciocínio Baseado em Casos na linguagem de programação lógica PROLOG. Basicamente, o protótipo é composto pela Rede Neural ART1, módulos de recuperação, reuso, avaliação/reparo e aprendizado de casos e por uma Base de Casos. A rede ART1 é responsável por agrupar os casos que inicialmente irão compôr a Base de Casos em clusters e posteriormente encontrar o cluster mais semelhante para um caso corrente, matching parcial. Os casos são organizados sequencialmente na Base de Casos, indexados pelo cluster correspondente. Quando um caso corrente não se assemelha a nenhum cluster definido anteriormente, a rede pode aprender este novo cluster sem detrimento dos clusters previamente definidos. Quando isto ocorre diz-se que o sistema de Raciocínio Baseado em Casos aprendeu.

O domínio culinário foi utilizado para investigar esta integração. Cada caso utilizado é composto pelos ingredientes da receita, caloria total, tempo de preparo 
e modo de preparo. Para treinar a rede, os casos somente dipõem de informações referentes à ausência ou presença de determinados ingredientes. Na Base de Casos todas as informações referentes à receita estão disponíveis.

Os testes realizados envolveram a variação de alguns parâmetros, $\rho$ e $L$, da rede ART1. O conjunto de treinamento foi composto por 27 casos e o conjunto de teste por 12 casos. O melhor resultado obtido foi a formação de 12 clusters e uma classificação correta de $85,18 \%$ para o conjunto de treinamento e $83,33 \%$ para o conjunto de teste. $\mathrm{O}$ mesmo conjunto de treinamento foi aplicado ao algoritmo de clustering K-Nearest Neighbor e o resultado obtido foi a formação de 9 clusters e uma classificação correta de $66,66 \%$. O conjunto de teste também foi aplicado a este algoritmo tendo como resultado $75 \%$ de associação correta para os padrões do conjunto de teste.

Mesmo sendo os resultados dos testes realizados favoráveis ao modelo proposto não se pode afirmar sua superioridade na formação correta de clusters e associação correta dos casos apresentados posteriormente ao sistema devido a natureza e ao número pequeno de casos do conjunto de treinamento e de teste. No entanto, pode-se afirmar que este é um modelo promissor no que se refere à recuperação e aprendizado de casos.

Neste sistema, os casos são organizados dentro de clusters. Cada cluster possui um protótipo que o representa, facilitando a recuperação do cluster mais semelhante a um novo caso, já que o sistema deve comparar o novo caso somente ao protótipo de cada cluster. Com isto reduz-se também o número de casos candidatos que deverão ser analizados para a seleção do melhor caso, porque estes casos serão apenas do cluster selecionado. A indexação dos clusters é simplificada pela Rede Neural. A rede é responsável por extrair as características relevantes de cada cluster e armazená-las de forma a utilizá-las posteriormente. O aprendizado de um novo cluster ocorre diretamente, bastando para isto incorporar um novo neurônio na camada de saída da rede ART1 e atualizar seus pesos.

\subsection{Limitações do Modelo}

O conhecimento manuseado por Redes Neurais deve estar completamente representado na forma númerica. Já o conhecimento utilizado por Raciocínio Baseado em Casos pode ser codificado simbolicamente. Para o domínio que se utilizou neste trabalho, domínio culinário, algumas informações referentes às receitas são difíceis de serem codificadas numericamente, por exemplo, o modo de preparo. Optou-se portanto em compor os casos para treinar a Rede Neural somente com 
informações referentes aos ingredientes de cada caso. O sistema, por exemplo, não pode sugerir um prato no qual o usuário queira utilizar fritura.

O número de ingredientes disponíveis do domínio culinário é muito grande. Neste trabalho os ingredientes foram limitados a um pequeno conjunto dos ingredientes mais utilizados. Os pratos foram definidos utilizando somente os ingredientes deste conjunto. Isto reduziu o tamanho dos conjuntos de treinamento e teste dificultando um estudo estatístico comparativo do modelo proposto.

\subsection{Contribuições}

A principal contribuição deste trabalho foi a integração de dois grandes paradigmas, Raciocínio Baseado em Casos e Redes Neurais. Ao unir paradigmas tão diferentes surgiram alguns problemas que suas soluções contribuiram com a pesquisa nestas duas àreas. Dentre eles pode-se citar: a representação do conhecimento, conforme comentado na Seção 7.2 deste capítulo; a difícil tarefa em se capturar o conhecimento a ser utilizado, principalmente se o conhecimento não é familiar ao projetista do sistema; enfim, a dificuldade e complexidade envolvidos no desenvolvimento de um sistema de Raciocínio Baseado em Casos a partir de suas definições teóricas.

\subsection{Trabalhos Futuros}

Este trabalho possui muitos pontos que poderão ser desenvolvidos posteriormente, dando continuidade à pesquisa envolvendo Raciocínio Baseado em Casos e Redes Neurais.

Os módulos de reuso de casos e revisão/reparo de casos são realizados, no protótipo implementado, pelo usuário manualmente. Posteriormente, estes módulos poderiam ser automatizados utilizando até mesmo outros paradigmas.

Os casos do domínio culinário que foram utilizados para treinar a rede ART1 eram compostos pelos ingredientes principais de cada prato. Em uma estrutura mais complexa para representar os casos poderia-se utilizar mais informações para indexá-los.

Outras redes, que possuem aprendizado incremental, poderiam ser utilizadas para recuperação e aprendizado dos casos. Por exemplo, a rede ARTMAP que possue 
aprendizado supervisionado e incremental; ou a rede ART2 que também possue aprendizado incremental e aceita como entrada vetores de valores reais além de outras redes que permitam aprendizado incremental. Poderiam também ser utilizados outros domínios que dispõem de um número maior de casos para testar o comportamento do sistema. 


\section{Referências Bibliográficas}

[Aamodt 94] Aamodt, A.; Plaza, E. Case-Based Reasoning: Foundational Issues, Methodological Variations and System Approaches. AI Communications, vol. 7, n. 1, pp. 39-59, March, 1994.

[Althoff 89]

Althoff, K. D. Knowledge Acquisition in the Domain of CNC Machine Centers; the MOLTKE Approach. In Boose, J.; Gaines, B.; Ganascia, J. G. (eds.): EKAW-89 Third European Workshop on Knowledge-Based Systems, Paris, pp. 180-195, July, 1989.

[Ashley 91] Ashley, K. Modeling Legal Arguments: Reasoning with Cases and Hypotheticals. MIT Press, Bradford Books, Cambridge, 1991.

[Bareiss 89] Bareiss, R. Exemplar-Based Knowledge Acquisition: A Unified Approach to Concept Representation, Classification, and Learning. Boston, Academic Press, 1989.

[Barletta 91] Barletta, R. An Introduction to Case-Based Reasoning. AI Expert, pp. 43-49, August, 1991.

[Barnden 92] Barnden, J.; Srinivas, K. Overcoming Rule-Based Rigidity and Connectionist Limitation Through Massively Parallel Case-Based Reasoning. International Journal of ManMachine Studies, vol. 36, n. 2, pp. 221-246, 1992.

[Bartfai 94] Bartfai, G. Hierarchical Clustering with ART Neural Network. Technical Report CS-TR-94/1, Department of Computer Science, Victoria University of Wellington, New Zealand, January, 1994.

[Bartfai 95] Bartfai, G. An ART-based Modular Architecture for Learning Hierarchical Clusterings. Technical Report CS-TR-95/3, De- 
[Beale 90]

[Branting 91]

[Bryson 69]

[Carpenter 87a]

[Carpenter 87b]

[Carpenter 90]

[Carpenter 91a]

[Carpenter 91b]

[Carpenter 91c] partment of Computer Science, Victoria University of Wellington, New Zealand, February, 1995.

Beale, R.; Jackson, T. Neural Computing: An Introduction. Adam Hilger, 1990.

Branting, B. Exploiting the Complementarity of Rules and Precedents with Reciprocity and Fairness. Proceedings from the Case-Based Reasoning Workshop, pp. 39-50, May, 1991.

Bryson, A. E.; Ho, Y. C. Applied Optimal Control. New York: Blaisdell, 1969.

Carpenter, G.; Grossberg, S. A Massively Parallel Architecture for a Self Organizing Neural Pattern Recognition Machine. Computer Vision, Graphics, and Image Processing, vol. 37, pp. 54-115, 1987.

Carpenter, G.; Grossberg, S. ART2: Self-Organization of Stable Category Recognition Codes for Analog Input Patterns. Applied Optics, vol. 26, n. 23, pp. 4919-4930, December, 1987.

Carpenter, G.; Grossberg, S. ART3: Hierarchical Search Using Chemical Transmitters in Self-Organizing Pattern Recognition Architectures. Neural Networks, vol. 3, pp. 129-152, 1990.

Carpenter, G.; Grossberg, S.; Rosen, D. B. ART2a: An Adaptive Resonance Algorithm for Rapid Category Learning and Recognition. Neural Networks, vol. 4, pp. 493-504, 1991.

Carpenter, G.; Grossberg, S.; Reynolds, J. H. ARTMAP: Supervised Real-Time Learning and Classification of Nonstationary Data by a Self-Organizing Neural Network. Neural Networks, vol. 4, pp. 565-588, 1991.

Carpenter, G.; Grossberg, S.; Rosen, D. B. Fuzzy ART: Fast Stable Learning and Categorization of Analog Patterns by an Adaptive Resonance System. Neural Networks, vol. 4, pp. 759-771, 1991. 
[Carpenter 92] Carpenter, G.; Grossberg, S.; Markuzon, N.; Reynolds, J. H.; Rosen, D. B. Fuzzy ARTMAP: A Neural Network Architecture for Incremental Supervised Learning of Analog Multidimensional Maps. IEEE Transactions on Neural Networks, vol. 3, n. 5, pp. 698-713, September, 1992.

[Fairhurst 88] Fairhurst, M. C. Computer Vision for Robotic Systems: An Introduction. Prentice Hall, 1988.

[Fausett 94] Fausett, L. Fundamentals of Neural Networks. Architectures, Algorithms, and Applications. Prentice Hall International Editions, 1994.

[Feigenbaum 63] Feigenbaum, E. A. The Simulation of Natural Learning Behavior. In Computers and Thought, (eds) Feigenbaum, E. A.; Feldman, J. New York: McGraw-Hill, 1963.

[Fu 94]

Fu, L. Rule Generation from Neural Networks. IEEE Transactions on Systems, Man, and Cybernetics, vol. 24, n. 8, August, 1994.

[Gallant 93] Gallant, S. I. Neural Network Learning and Expert Systems. The MIT Press, England, 1993.

[Goonatilake 95] Goonatilake, S.; Khebbal, S. Intelligent Hybrid Systems. John Wiley \& Sons, 1995.

[Grossberg 76a] Grossberg, S. Adaptive Pattern Classification and Universal Recoding, I: Parallel Development and Coding of Neural Feature Detectors. Biological Cybernectics, vol. 23, pp. 121-134, 1976.

[Grossberg 76b] Grossberg, S. Adaptive Pattern Classification and Universal Recoding, II: Feedback, Expectation, Olfacation, and Illusions. Biological Cybernectics, vol. 23, pp. 187-202, 1976.

[Gurney] Gurney, K. Notas de Aula. Dept. Human Sciences, Brunel University, Uxbridge, Middx.

[Hall 92] Hall, C. Neural Net Technology: Ready for Prime Time. IEEE Expert, pp. 2-4, December, 1992.

[Hammerstrom 93] Hammerstrom, D. Neural Networks at Work. IEEE Spectr., pp. 26-32, June, 1993. 
[Hammond 89] Hammond, K. J. Case-Based Planning Viewing Planning as a Memory Task. Academic Press, Boston, 1989.

[Hebb 49]

[Heims 82]

Hebb, D. O. The Organization of Behavior. Wiley, New York, 1949.

Heims, S. J. John von Neumann and Norbert Weiner - From Mathematics to the Technologies of Life and Death. Academic Press, 1982.

[Heins 95]

[Hinrichs 88]

Heins, L. G., Tauritz, D. R. Adaptative Resonance Theory (ART): An Introduction. May/June, 1995.

Hinrichs, T. R. Towards and Architecture for Open World Problem Solving. In Proceedings: Workshop on Case-Based Reasoning (DARPA), Clearwater, Florida. San Mateo, CA: Morgan Kaufmann, 1988.

[Hinrichs 92] Hinrichs, T. R. Problem Solving in Open Worlds: a Case Study in Design. Northvale, NJ: Erlbaum, 1992.

[Hoffman 93] Hoffman, T. Don't Choose Technology Without Him. Computerworle, vol. 27, n. 4, January, 1993.

[Hopfield 82] Hopfield, J. J. Neural Networks and Physical Systems with Emergent Collective Computational Abilities. Proceedings of the National Academy of Sciences, USA, vol. 79, pp. 25542588, April, 1982.

[Klimasauskas 91] Klimasauskas, C. C. Neural Nets Tell Why. Dr. Dobb's Journal, pp. 16-24, April, 1991.

[Kohonen 84] Kohonen, T. Self-Organization and Associative Memory. Springer Verlag, 1984.

[Kolodner 83a] Kolodner, J. L. Maintaining Organization in a Dynamic Long-Term Memory. Cognitive Science, vol. 7, pp. 243-280, 1983 .

[Kolodner 83b] Kolodner, J. L. Reconstructive Memory, a Computer Model. Cognitive Science, vol. 7, pp. 281-328, 1983.

[Kolodner 84] Kolodner, J. L. Retrieval and Organization Strategies in Conceptual Memory: A Computer Model. Northvale, NJ: Erlbaum, 1984. 
[Kolodner 87] Kolodner, J. L. Capitalizing on Failure Through Case-Based Inference. In Proceedings of the Ninth Annual Conference of the Cognitive Science Society. Northvale, NJ:Erlbaum, 1988.

[Kolodner 88] Kolodner, J. L.; Thau, R. Design and Implementation of a Case Memory. Georgia Institute of Technology, School of Information and Computer Science, Technical Report GITICS-88/34, Atlanta, 1988.

[Kolodner 89] Kolodner, J. L.; Simpson, R. L. The MEDIATOR: Analysis of an early case-based problem solver. Cognitive Science, vol. 13, n. 4, pp. 507-549, 1989.

[Kolodner 92] Kolodner, J. L. An Indtroduction to Case-Based Reasoning. Artificial Intelligence Review, n. 6, pp. 3-34, 1992.

[Kolodner 93] Kolodner, J. L. Case-Based Reasoning. Kaufmann, 1993.

[Koton 89] Koton, P. Using Experience in Learning and Problem Solving. Ph. D. Thesis, Department of Computer Science, MIT, 1989.

[Krovvidy 93] Krovvidy, S.; Wee, W. G. Wastewater Treatment Systems from Case-Based Reasoning. Machine Learning, vol. 10, pp. 341-363, 1993.

[LeCun 86] Le Cun, Y. Learning Processes in an Asymmetric Threshold Network. In Bienenstock, E.; Fogelman-Souli, F.; \& Weisbuch, G. (eds.), Disordered Systems and Biological Organization. NATO ASI Series, F20, Berlin: Springer-Verlag, 1986.

[Lopes 95] Lopes, A. A.; Monard, M. C. Raciocínio Baseado em Casos Dissertação apresentada ao Intituto de Ciências Matemáticas de São Carlos, Julho, 1995.

[López 90] López, B.; Plaza, E. Case-Based Learning of Strategic Knowledge. Centre d'Estudis Avançats de Blanes, CISC, Report de Recerca GRIAL 90/14, Blanes, Spain, October, 1990.

[Malek 95]

Malek, M. A Connectionist Indexing Approach for CBR Systems In Aamodt, A.; Veloso, M. (Eds.), Preceedings of First International Conference on Case-Based Reasoning Research and Development, pp. 520-527, Sesimbra, Portugal, October, 1995. 
[McCulloch 43]

[Mendes 97]

[Milaré 97a]

[Milaré 97b]

[Minsky 69]

[Murre 89]

[Parker 85]

[Pau 92]

[Petridis 93]

[Plaza 90]
McCulloch, W. S.; Pitts, W. H. A Logical Calculus of the Ideas Immanent in Nervous Activity. Bulletin of Mathematical Biophysics, vol. 5, pp. 115-133, 1943.

Mendes Filho, E. F.; Carvalho, A. C. P. L., Projeto Evolucionário de Redes Neurais Artificiais para Avaliação de Crédito Financeiro. Dissertação apresentada ao Intituto de Ciências Matemáticas de São Carlos, 1997.

Milaré, C. R.; Batista, G. E. A. P. A.; Monard, M. C. Uma Ferramenta para Extração de Conhecimento de Redes Neurais. Anais do XXIV Seminário Integrado de Hardware e Software, pp. 59-70, Agosto, 1997.

Milaré, C. R.; Carvalho, A. C. P. L. Protótipo de um Sistema Híbrido de Raciocínio Baseado em Casos. Submetido para publicação pela Biblioteca do Instituto de Ciências Matemáticas de São Carlos - USP, 1997.

Minsky, M.; Papert, S. Perceptrons. MIT Press, Cambridge, 1969.

Murre, J. M. J.; Phaf, R. H.; Wolters, G. CALM Networks: A Modular Approach to Supervised and Unsupervised Learning. Proceedings of the International Joint Conference on Neural Networks Washington DC, 1. New York: IEEE Press, pp. 649-665, 1989.

Parker, D. Learning Logic. Technical Report TR-87, Cambridge, MA: Center for Computational Research in Economics and Management Science, MIT, 1985.

Pau, L. F.; Götzche, T. Explanation Facility for Neural Networks. Journal of Intelligent and Robotic Systems, vol. 5, pp. 193-206, 1992.

Petridis, V.; Paraschidis, K. Structural Adaptation Based on a Simple Learning Algorithm. In Proceedings of the International Joint Conference on Neural Networks, vol. 1, pp. 621-623, 1993.

Plaza, E.; Mántaras, L. R. A Case-Based Apprentice that Learns from Fuzzy Examples. Proceedings, ISMIS, Knoxville, Tennessee, pp. 420-427, 1990. 
[Porter 86]

[Porter 90]

[Reategui 94]

[Reategui 95]

[Richter 91]

[Ripley 94]

[Rosenblatt 62]

[Rumelhart 86a]

[Rumelhart 86b]

[Rumelhart 86c]
Porter, B. W.; Bareiss, R. PROTOS: An Experiment in Knowledge Acquisition for Heuristic Classification Tasks. Proceedings of the First International Meeting on Advances in Learning (IMAL), Les Arcs, France, pp. 159-174, 1986.

Porter, B. W.; Bareiss, R.; Holte, R. C. Concept Learning and Heuristic Classification in Weak-Theory Domains. Artificial Intelligence, v.45, pp.229-263, 1990.

Reategui, E.; Campbell, J. A. A Classification System for Credit Card Transactions. In Keane, M.; Haton, J.; Manago, M. (Eds.), Preceedings of European Workshop on CaseBased Reasoning, France, pp. 167-174, 1994.

Reategui, E.; Campbell, J. A.; Borghetti, S. Using a Neural Network to Learn General Knowledge in a Case-Based System. In Aamodt, A.; Veloso, M. (Eds.), Preceedings of First International Conference on Case-Based Reasoning Research and Development, Sesimbra, Portugal, pp. 528-537, October, 1995.

Richter, A. M.; Weiss, S. Similarity, uncertainty and casebased reasoning in PATDEX. Boyer, T. S. (ed.): Automated reasoning, essays in honour of Woody Bledsoe, Kluwer, pp. 249-265, 1991.

Ripley, B. D. Flexible Non-Linear Approaches to Classification. In: Cherkassky, V.; Friedman, J. H.; Wechsler, H. (Eds). From Statistics to Neural Networks. Theory and Pattern Recognition Applications. Springer, Berlin, pp. 105-126, 1994.

Rosenblatt, F. Principles of Neurodynamics. Spartan Books, 1962.

Rumelhart, D. E.; McClelland, J. L. Parallel Distributed Processing. MIT Bradford Press, Cambridge, vol. 1, 1986.

Rumelhart, D. E.; Hilton, G. E.; Williams, R. J. Learning Representations by Back-Propagation Errors. Nature, vol. 323, pp. 533-536, October, 1986.

Rumelhart, D. E.; Hilton, G. E.; Williams, R. J. Parallel Distributed Processing: Explorations in the Microstructure of Cognition. MIT Press, Cambridge, vol. 1, pp. 318-362, 1986 . 
[Sase 93]

[Schank 77]

[Schank 82]

[Schank 89]

[Schwartz 92]

[Shandle 93]

[Sharma 88]

[Simpson 85]

[Skalak 92]

[Slade 91]
Sase, M.; Matsui, K.; Kosugi, Y. Inter-Generational Architecture Adaptation of Neural Networks. In Proceedings of the International Joint Conference on Neural Networks, vol. 3, pp. 2941-2944, 1993.

Schank, R. C.; Adelson, R. P. Scripts, Plans, Goals and Understanding an Inquiry into Human Knowledge Structures. Lawrence Erlbaum Associates, Publishers, Hillsdale, New Jersey, 1977.

Schank, R. C. Dynamic Memory: A Theory of Reminding and Learning in Computers and People. Cambridge University Press, 1982.

Schank, R. C.; Riesbeck, C. K. Inside Case-Based Reasoning. Lawrence Erlbaum Associates, Publishers, 1989.

Schwartz, E. I.; Treece, J. B. Smart Programs Go to Work: How Applied-Intelligence Software Makes Decisions for the Real World. Bus. Week, pp. 97-105, March, 1992.

Shandle, J. Neural Networks are Ready for Prime Time. Elect. Des., vol. 41, n. 4, pp. 51-58, February, 1993.

Sharma, S.; Sleeman, D. REFINER: A Case-Based Differential Diagnosis Aide for Knowledge Acquisition and Knowledge Refinement. EWSL 88: Proceedings of the Third European Working Session on Learning, Pitman, pp. 201-210, 1988.

Simpson, R. L. A Computer Model of Case-Based Reasoning in Problem Solving: An Investigation in the Domain of Dispute Mediation. Georgia Institute of Technology, School of Information and Computer Science Technical Report GITICS-85/18, Atlanta, 1985.

Skalak, C. B.; Rissland, E. Arguments and Cases: An Inevitable Twining. Artificial Intelligence and Law, An International Journal, pp. 3-48, 1992.

Slade, S. Case-Based Reasoning: A Research Paradigm. IA Magazine, pp. 43-49, 1991. 
[Sycara 88]

$\begin{aligned} \text { [Venkatamaran 93] } & \text { Venkatamaran, S.; Krishnan, R.; Rao, K. K. A Rule-Case } \\ & \text { Based System for Image Analysis. First European Workshop } \\ & \text { on Case-Based Reasoning, Posters and Presentations. Uni- } \\ & \text { versity of Kaiserslautern, vol. II, pp. 410-415, November, } \\ & 1993 .\end{aligned}$

[von Neumann 45] von Neumann, J. Frist Draft of a Report on the EDVAC. Reimpresso em B. Randell (ed.). The Origins of Digital Computers: Selected Papers. Berlim, Alemanha, Springer-Verlag, 1973.

[Wendel 93]

[Werbos 74]

[Werbos 89]

[Widrow 60]

[Widrow 94]

Sycara, K. Using Case-Based Reasoning for Plan Adaptation and Repair. Proceedings Case-Based Reasoning Workshop, DARPA. Clearwater Beach, Florida, Morgan Kaufmann (Ed.), pp. 425-434, 1988.

Wendel, O. Case Based Reasoning in a Simulation Environment for Biological Neural Networks. In First European Workshop on Case-Based Reasoning, (EWCBR'93) Presentation and Posters, (ed) Richter, M. M. et al. University of Kaiserslauten (Germany), vol. 1, pp. 1-5, 1993.

Werbos, P. Beyond Regression: New Tools for Prediction and Analysis in the Behavioral Sciences (Ph.D. Thesis). Cambridge, MA: Harvard U. Committee on Applied Mathematics, 1974.

Werbos, P. Backpropagation and Neural Control: A Review and Prospectus. Anais da International Joint Conference on Neural Networks (IJCNN), Nova York, IEEE, 1989.

Widrow, B.; Hoff, M. E. Adaptive Switching Circuits. Institute of Radio Engineers, Western Eletronic Show and Convertion, pp. 96-104, 1960.

Widrow, B.; Rumelhart, D. E.; Lehr, M. A. Neural Networks: Aplications in Industry, Business and Science. Communications of the ACM, March, vol. 37, n. 3, 1994. 